$\therefore \quad H C P / T 2289-01$

\title{
The Results of the Initial Feasibility Program on Cavitation Descaling Techniques for Pipes and Tubes Used in Geothermal Energy Plants
}

June 1978

Prepared For

U.S. Department of Energy

Assistant Secretary for Energy Technology

Division of Geothermal Energy

Under Contract No. E (49-18) 2289 


\section{DISCLAIMER}

This report was prepared as an account of work sponsored by an agency of the United States Government. Neither the United States Government nor any agency Thereof, nor any of their employees, makes any warranty, express or implied, or assumes any legal liability or responsibility for the accuracy, completeness, or usefulness of any information, apparatus, product, or process disclosed, or represents that its use would not infringe privately owned rights. Reference herein to any specific commercial product, process, or service by trade name, trademark, manufacturer, or otherwise does not necessarily constitute or imply its endorsement, recommendation, or favoring by the United States Government or any agency thereof. The views and opinions of authors expressed herein do not necessarily state or reflect those of the United States Government or any agency thereof. 


\section{DISCLAIMER}

Portions of this document may be illegible in electronic image products. Images are produced from the best available original document. 
Available from:

National Technical Information Service (NTIS)

U.S. Department of Commerce

5285 Port Royal Road

Springfield, Virginia 22161

Price: Printed copy: $\$ 5.25$

Microfiche: $\$ 3.00$ 
HCP/T2289-01

UC-66d

\section{The Results of the Initial Feasibility Program on Cavitation Descaling Techniques for Pipes and Tubes Used in Geothermal Energy Plants}

June 1978

Prepared By

Daedalean Associates, Inc.

For

U.S. Department of Energy

Assistant Secretary for Energy Technology

Division of Geothermal Energy

Washington, DC 20545

Under Contract No. E (49-18) 2289

NOTE:

This publication was prepared for the Energy Research and Development Administration (ERDA) prior to the establishment of the Department of Energy (DOE). Therefore, wherever ERDA is mentioned, its functions have been transferred to DOE. 


\section{NOTICE}

This report was prepared as an account of work sponsored by the United States Government. Neither the United States nor the United States Department of Energy, nor any of their employees, makes any warranty, express or implied, or assumes any legal liability or responsibility for the accuracy, completeness, or usefulness of any information, apparatus, product, or process disclosed, or represents that its use would not infringe privately owned rights. Reference herein to any specific commercial product, process, or service by trade name, mark, manufacturer, or otherwise, does not necessarily constitute or imply its endorsement, recommendation, or favoring by the United States Government or any agency thereof. The views and opinions of authors expressed herein do not necessarily state or reflect those of the United States Government or any agency thereof. 
TABLE OF CONTENTS

Page

ACKNOWLEDGMENTS ..................... i

LIST OF FIGURES ....................... iv

1.0 INTRODUCTION..................... 1

1.1 Background..................... 1

1.2 Problem Definition.................. 2

1.3 Program Objectives................... 3

1.4 Description of Cavitation Phenomena...... 5

1.5 Cavitation Inception Parameter.......... 6

2.0 CONTROLLED INTENSITY CAVITATION EROSION WATER

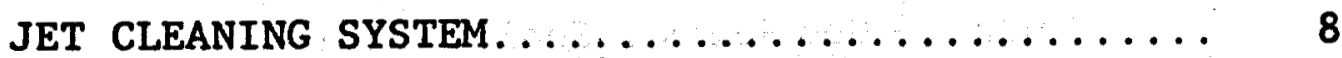

2.1 High Pressure Water Flow and Delivery

Subsystem to the Cleaning Nozzles......... 8

2.2 Control and Instrumentation Subsystem...... 10

2.3 Nozzle Performance and Scale Removal

Evaluation subsystem............... 10

3.0 HYDRAULIC PERFORMANCE OF CAVITATING NOZZLES

AT HIGH VELOCITIES ................... 13

3.1 Effect of Pressure and Nozzle Diameter.... 13

3.2 Effect of Reynolds Number............. 15 
4.0 EFFECT OF NOZZLE SIZE ON THE INTENSITY OF

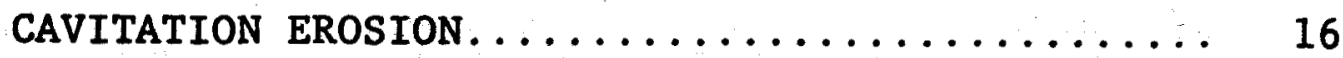

4.1 Intensity of Cavitation Erosion......... 16

4.2 Effect of Nozzle Pressures and Sizes...... 18

4.3 Effect of Jet Velocity................ 19

5.0 INFLUENCE OF NOZZLE DISTANCE ON THE INTENSITY OF CAVITATION EROSION................... 20

5.1 Effect of Nozzle Distance............ 20

5.2 Nozzle Size...................... 22

6.0 EFFECT OF PRESSURE ON CLEANING RATE........... 24 6.1 Types of Geothermal Scales Cleaned........ 24 6.2 Depth of Scale Removed............... 24 6.3 Volume of Scale Removed.............. 25 6.4 Cleaning Rates Achieved.............. 26 6.5 Quality of Cleaned Surfaces............ 27

7.0 CONCLUSIONS AND RECOMMENDATIONS ........... 28 REFERENCES ......................... 30 


\section{LIST OF FIGURES}

FIGURE 1 SEVERE SCALING OF FEEDER PIPES LEADING TO FLASHERS AND SCRUBBERS. MINERAL DEPOSITS 3" TO 4" THICK HAVE ACCUMULATED ON FEEDER PIPES IN OPERATION

FIGURE 2 SCHEMATIC FLOW DIAGRAM FOR HYDROJET TEST FACILITY

FIGURE 3 SCHEMATIC OF CONTROL PANEL FOR CAVITATION DESCALING TEST FACILITY

FIGURE 4 PHOTOGRAPHIC VIEW OF CONTROL PANEL SHOWING FLOW METERS AND PRESSURE GAUGES ALONG WITH THE ENVIRONMENTAL TEST CHAMBER AND ASSOCIATED VIEW PORTS

FIGURE 5 END SECTION VIEW OF TEST CHAMBER INDICATING DESCALING LANCE WITH SECTION OF SCALED PIPE

FIGURE 6 ENLARGED VIEW OF CLEANING LANCE IN PLACE PRIOR TO SCALE REMOVAL

FIGURE 7 LOSS COEFFICIENT FOR CAVITATING NOZZLES

FIGURE 8 EFFECT OF REYNOLDS NUMBER ON COEFFICIENT OF VELOCITY int $x$

FIGURE 9 INTENSITY OF CAVITATION EROSION VS NOZZLE SIZE AT CONSTANT PRESSURE

FIGURE 10 INTENSITY OF CAVITATION EROSION VS NOZZLE SIZE AT CONSTANT VELOCITIES

FIGURE 11 EFFECTIVE SCALE THICKNESS THAT CAN BE CLEANED WITHOUT AFFECTING THE PIPE WALL 
FIGURE 12 THE EFFECT OF A CAVITATING SYSTEM ON THE PIPE WALL MATERIAL WITH AN INTENSITY OF $20,000 \mathrm{~W} / \mathrm{m}^{2}$

FIGURE 13 EFFECT OF STAND-OFF DISTANCE ON THE INTENSITY OF CAVITATION EROSION FOR A 0.023 INCH DIAMETER NOZZLE

FIGURE 14 EFFECT OF STAND-OFF DISTANCE ON THE INTENSITY OF CAVITATION EROSION FOR A 0.032 INCH DIAMETER NOZZLE

FIGURE 15 EFFECT OF STAND-OFF DISTANCE ON THE INTENSITY OF CAVITATION EROSION FOR A 0.037 INCH DIAMETER NOZZLE

FIGURE 16 RELLATIONSHIP BETWEEN PENETRATION INTO SCALE AND THE NOZZLE PRESSURE FOR A ONE SECOND EXPOSURE TO A CAVITATING JET

FIGURE 17 RELATIONSHIP BETWEEN PENETRATION INTO SCALE AND THE NOZZLE PRESSURE FOR A SIXTY SECONDS EXPOSURE TO A CAVITATING JET

FIGURE 18 RELATIONSHIP BETWEEN THE VOLUME OF SCALE CLEANED FROM A THREE CUBIC INCH TEST SAMPLE AND THE NOZZLE PRESSURE FOR A ONE SECOND EXPOSURE TO A CAVITATING JET

FIGURE 19 RELATIONSHIP BETWEEN THE VOLUME OF SCALE CLEANED FROM A THREE CUBIC INCH TEST SAMPLE AND THE NOZZLE PRESSURE FOR A SIXTY SECONDS EXPOSURE TO A CAVITATING JET

FIGURE 20 CLEANING RATE AS A FUNCTION OF ORIFICE DIAMETER WITH RESPECT TO NOZZLE PRESSURE FOR CONCAVER CLEANING SYSTEM IN 6 INCH DIAMETER SCALED PIPE AS RECEIVED FROM THE IMPERIAL VALLEY GEOTHERMAL FIELDS 
vi

FIGURE 21 LONGITUDINAL SECTION OF PIPE SHOWING THICKNESS OF SCALE AND QUALITY OF CLEANED SURFACE AFTER APPLICATION OF DESCALING TECHNIQUE

FIGURE 22 PHOTOGRAPHIC VIEW OF TWO FOOT LONGITUDINAL SECTION SHOWING EFFECT OF CAVITATION CLEANING AND THE INITIAL SCALE PRIOR TO THE APPLICATION OF THE TECHNIQUE 


\section{THE RESULTS OF THE INITIAL FEASIBILITY \\ PROGRAM ON CAVITATION DESCALING \\ TECHNIQUES FOR PIPES AND TUBES \\ USED IN GEOTHERMAL ENERGY PLANTS}

\subsection{INTRODUCTION}

\subsection{Background}

Since 1970, increasing national attention has been focussed on the potential of using geothermal resources for electrical power generation. Significant amounts of electric power produced from geothermal steam ( 790 megawatts as of 1972) have been generated in various countries throughout the world including the United States, Italy, New Zealand, Iceland, Japan, Mexico, and the Soviet Union. Commercial geothermal development in the United States has centered in northern California (Geysers), and in southern California (Imperial Valley). A combination of the Magma Power Co., the Union Oil Co., and the Thermal Power Co., has been drilling geothermal wells and producing steam in northern California since 1960. The Pacific Gas and Electric Co. purchases the steam for the generation of electricity. The Imperial Valley is a wet steam geothermal resource area currently being considered by major oil companies (the Union oil Co.) and electrical utilities (the San Diego Gas and Electric Co.) for commercial geothermal exploitation. 
This valley is one of approximately 1,000 geothermal hot water systems presently identified in the United States. A recent survey (1)* has determined that the total power potenial in the United States from geothermal hot water systems is between 1 million and 10 million megawatts, with an associated resource life estimated between 100 and 300 years.

\subsection{Problem Definition}

The potential of geothermal energy is well documented and the U. S. Government through the Energy Research and Development Administration (USERDA) is establishing a strong committment to the utilization of geothermal energy as an alternate power source for heat and electricity. Plants are under construction and in operation at various locations throughout the country with technical and operational problems being identified and corrected in order to establish a viable alternate energy source that is economically competitive.

An operational problem of particular interest is the significant amount of solid mineral particles that are suspended in the steam and hot water flow. These particles subsequently deposit on the surfaces of the pipes and tubes at critical locations in the plant and the associated sedimentation process can clog the piping systems and heat exchanger

\footnotetext{
* Numbers in parenthesis refer to references at the end of this report.
} 
tubes in operation. Serious scaling problems have been encountered in the feeder pipes leading to the flashers and scrubbers as shown in Figure 1. These feeder pipes have experienced scaling that reduced the size of the pipe from 9" to less than 2" in internal diameter. Currently, the cleaning procedure for these pipes and heat exchanger surfaces is a delicate, time consuming and costly operation which seriously affects the economic viability of energy production from geothermal sources. Moreover, the problem is further complicated by the fact that existing cleaning techniques do not adequately remove the mineral deposits.

\subsection{Program Objectives}

Because of the lack of an effective pipe cleaning and descaling technique, DAEDALEAN ASSOCIATES, Inc. (DAI), under contract to USERDA, Division of Geothermal Energy (Utilization Technology Branch) has conducted a research and development program to utilize the phenomenon of cavitation for geothermal cleaning and descaling applications. With this technique, water is pumped under high pressure through a properly designed cavitating system. The cavitating system consists of a properly designed pump and motor combination with an appropriate nozzle configuration. The high speed jet emerging from the nozzle produces cavitation bubbles which are carried by the jet to the hard mineral scale. The system 
design permits the bubbles to collapse against the scaled surface with a predetermined intensity of erosion (2).

The purpose of the program described in this report is to develop input parameters and to establish design specifications for a cavitating hydrojet descaling system for pipe cleaning applications. Under this program, various design input parameters have been identified in order to establish associated cleaning rates for the type of scale and thickness that has been obtained from field operating environments. Specifically, this report addresses: 1) the relationship between the jet speed and the cleaning rate; 2) the size and geometry of the nozzle as related to the surface area cleaned; 3 ) the minimum intensity of erosion for cavitation cleaning; 4) the optimum cavitation parameter as a function of cleaning rate; and, 5) the specific horsepower requirements for the most efficient cleaning rates as defined by the cavitation descaling system. These specific areas of technical evaluation establish the design guidelines for the cavitating hydrojet descaling technique in order to effectively and efficiently remove geothermal scale. This report discusses the phenomenon of cavitation and the cavitation inception parameter (3) applicable to the descaling and cleaning technique. The experimental facility, test procedures, results, discussion of data 
and conclusions and recommendations for the initial feasibility program are identified.

\subsection{Description of Cavitation Phenomena}

In an engineering context, cavitation is defined as the process and formation of the vapor phase of a liquid when it is subjected to reduced pressures at constant ambient temperature. A liquid cavitates when vapor bubbles are observed to form and grow as a consequence of a pressure reduction. The phase transition is a result of a pressure change by hydrodynamic means, and the resulting two-phase flow composed of a liquid and its vapor is defined as a cavitating flow (4).

As cavitation initiates, tiny vapor bubbles form in rapid succession at the point of lowest pressure and are carried downstream by the flow into a zone of higher pressure. The bubbles immediately collapse when the vapor condenses. However, as each of the countless individual bubbles collapse, the resulting impact of opposing masses of liquid produces a localized pressure which is transmitted radially outward at the speed of sound. Boundary materials in the immediate vicinity are subject to localized fatigue failure as a result of the rapidly repeated stress reversals. The localized fatigure failure is the initiation of cavitation erosion.

An increase in the velocity of the flow beyond that required for incipient cavitation produces no further reduction 
in pressure at the point of cavitation, but characterizes an elongation. of the zone over which the vapor limit prevails. Moreover, the vapor bubbles increase in size until a stable vapor pocket is formed. Since the formation of the vapor pocket results in a change for the surrounding flow pattern, the pressure distribution changes accordingly. The vapor limit is maintained throughout the length of the cavitation pocket for a specific pressure differential. The program associated with this report utilizes the phenomenon of cavitation in order to develop a cleaning technique for geotherma1 pipe descaling applications.

\subsection{Cavitation Inception Parameter}

The cavitation number $(\sigma)$ is a useful index for characterizing the cavitation phenomenon. The nondimensional number is the ratio between the free stream vapor pressures and the stagnation pressure after a steady jet:

$$
\sigma=\frac{P_{0}-P_{v}}{\frac{3}{2} \rho V_{0}^{2}}
$$

where :

$$
\begin{aligned}
& P_{0}=\text { free stream pressure, } \\
& P_{v}=\text { vapor pressure of liquid, } \\
& v_{0}=\text { free stream velocity }
\end{aligned}
$$

and $\quad \rho=$ density of liquid. 
Whenever $\sigma$ is appreciably greater in numerical value than the minimum ordinate on the dimensionless pressure-distribution curve for a body of given, form, the occurrence of cavitation is not expected at any point on the boundary. Once $\sigma$ approximately equals the absolute magnitude of the minimum ordinate, conditions of incipient cavitation $\left(\sigma_{1}\right)$ prevail. At values of $\sigma$ below this critical limit, the pressure distribution initiates the formation of cavitation.

For body forms separating the flow, cavitation initiates within the fine-scale eddies formed at the interface. The formation of cavitation occurs before the boundary pressure attains the vapor limit. The magnitude of the cavitation inception parameter is determined analytically (5) or by actual measurement of the pressure distribution. The cavitation parameter is characterized from the pressure differential for the vapor pressure of the liquid and the chamber pressure as a function of the stream velocity. 
2.0 CONTROLLED INTENSITY CAVITATION EROSION WATER JET

CLEANING SYSTEM

The requirements for the design and assembly of the laboratory apparatus along with the establishment of the test facility have been accomplished. The design and completion of the test facility focused on the following main areas: a) pump selection, b) control panel assembly, and c) various test chamber designs. A detailed analysis of various pumps and pump manufacturers was conducted based on the selection criteria of flow rate ( 3 to $5 \mathrm{gpm}$ ), operating pressure ( 10 to $15 \mathrm{ksi}$ ), water operation and normal temperature operation in addition to fiscal considerations and delivery time.

The test facility consists of several subsystems for producing cavitating water jets and evaluating their effectiveness as a technique for scale removal. These subsystems include: 1) high-pressure water flow subsystem; 2) monitoring and control subsystem; and 3) nozzle performance and scale removal evaluation subsystem.

2.1 High Pressure Water Flow and Delivery Subsystem to the Cleaning Nozzles

The major component of the delivery system for the high-pressure water to the cleaning nozzles is a horizontal triplex plunger pump capable of delivering $4.2 \mathrm{gpm}$ at a developed pressure of $12,000 \mathrm{psi}$. The pump is powered by a 
$40 \mathrm{hp}, 460$ volt, $60 \mathrm{~Hz}, 3$ phase, electric motor via a multiple power band $V$-belt drive. The constant displacement pump produces the volume flow rate from a reciprocating action with close tollerance plunger diameters.

Complementing the high-pressure triplex plunger pump is a low pressure ( 30 psig) filtered water supply to the pump; a starter and circuit breaker protection for the motor, a rupture disc relief protection for the pump; and high-pressure valves and tubing for bypassing and control of the flow from the pump. Figure 2 is a schematic flow diagram for the test facility. Low pressure ( $30 \mathrm{psig}$ ) water is supplied to the high-pressure horizontal triplex plunger pump through a conventional water supply source. This flow can also be diverted to fill an environmental chamber for controlled condition testing of the cavitating nozzles or to fill a test chamber for evaluation of cavitating descaling cleaning rates. The water supply pressure to the pump is monitored to maintain a required positive suction head for effective operation of the force feed water lubricators. The flow through the high pressure nozzle is regulated by the nozzle pressure control and the nozzle by-pass valve. A nozzle pressure gauge 10cated at the discharge of the pump monitors the pressure at the nozzle. 


\subsection{Control and Instrumentation Subsystem}

Figure 3 is a schematic representation of the control panel for the test facility. The pump has a standard shunt-switch electric control and an auxilary power control. The control panel consists of varlous pressure gauges for nozzle and suction pressure in addition to specific pressure gauges for the environmental test chamber. The chamber pressure gauges are designated low range (0-160 psi), mid range (0-600 psi) and high range (0-1,500 psi) for accurate monitoring of the environmental tests. Independent controls are associated with each pressure indicator for gauge protection against excessive pressures. The flow meter control and the chamber pressure control actuate the flow meter and pressure gauges. The critical operating parameters can be monitored from the central control and the necessary functions can be performed in order to determine the loss coefficient measurements and to gather engineering data on specific orifice plate nozzle designs.

\subsection{Nozzle Performance and Scale Removal Evaluation}

\section{Subsystem}

Evaluation of loss coefficients and other measures of performance for the cavitating nozzles are conducted from a controlled environment test chamber. The design of the test chamber required proper location of the jet nozzle and 
standard test material in order to establish cavitation parameters. The nozzle and test material location were properly designed and Incorporated into the environmental test chamber with a variable distance capability. Figure 4 is a photographic view of the control panel and test chamber. The chamber has a pressure capability of 500 psi, a test material size capability of 6" 6 6" $\times 2$ ", an offset distance capability of 9" and view ports for cavitation erosion and intensity determination from bubble formation. The chamber permits visual and quantitative analysis of cavitating jets. The flexibility of this chamber makes possible the evaluation of many different types, sizes, and configurations of nozzles in terms of velocity, efficiency and intensity for varying operating pressure conditions and nozzle standoff distances. Additionally, the chamber allows for the determination of erosion resistance of materials to cavitating jets.

Evaluation of the scale removal technique is accomplished through a large test tank and two test stands. Sections of scaled pipe are supported inside the rectangular tank as shown in Figure 5 . The test tank permits a series of experiments for cleaning rate data. Optimum cleaning rates for diferent types of scale with various nozzle configurations and velocities have been determined. The capability exists to vary the speed at which the nozzle moves through the section 
of scaled pipe. The nozzle is attached to a rigid section of high-pressure tubing which in turn is mounted to the piston of a pneumatic cylinder. A control valve activates the cylinder. By varying the regulated air pressure supplied to the valve, different rates of travel of the nozzle through the specimen can be obtained. The test chamber has the capability to rotate sections of pipe. Figure 6 is a sectional view of the nozzle entering the scaled pipe. The nozzle section is attached to a trolley which is connected to the air operated pneumatic cylinder. Along with the capability to vary the operating pressure of the cavitating nozzle in the large test chamber, the effects of different nozzle diameters on the cleaning rates can also be evaluated.

An additional test stand was used to evaluate the erosion resistance of the geothermal scales with small samples of the scaled pipe. In this configuration, detailed observation of the interaction between the cavitating jet and the scale was made. A mechanical set-up was used to determine the erosion thresholds for the scale and the estimates of cleaning rates for scale thicknesses as a function of pipe diameter. 


\subsection{HYDRAULIC PERFORMANCE OF CAVITATING NOZZLES AT HIGH}

\section{VELOCITIES}

The experimental apparatus described in the previous section was designed, fabricated, and calibrated during the initial phase of this program. The necessary experimental studies and the feasibility demonstration were successfully conducted with proper utilization of this equipment. In order to understand the hydrodynamic performance of cavitating nozzles at very high velocities, detailed experiments were conducted on the coefficient of velocity for three nozzle sizes in the pressure range of 8,000 psi to 12,000 psi. The coefficient of velocity is an indication of the hydrodynamic loss through the nozzle and was determined by measuring the actual velocity as a function of the theoretical calculated velocity.

\subsection{Effect of Pressure and Nozzle Diameter}

The theoretical velocity through the nozzle is calculated from Bernoullis equation. The actual velocity through the nozzle is calculated by measuring the discharge through the nozzle and dividing the discharge by the crosssectional area of the nozzle. The coefficient of velocity is then obtained by calculating the ratio of the actual measured velocity to the theoretical velocity. Actual hydrodynamic losses through the system can be obtained from such 
measurements with the following equation:

$$
\text { Losses }=k_{2} \rho V^{2} \quad \frac{1}{C_{v}^{2}}-1
$$

where:

$$
\begin{aligned}
& \rho=\text { the density of liquid } \\
& v=\text { the velocity through orifice } \\
& C_{v}=\text { the coefficient of velocity }
\end{aligned}
$$

The coefficient of velocity for non-cavitating orifices varies from 0.95 to 0.99 at low pressures. In order to evaluate the influence of high pressures on cavitating nozzles, detailed experiments were conducted over a range of pressures varying from 8,000 psi to 12,000 psi. Orifice plates of varying diameter were used for these experiments. The experimentally determined coefficients of velocity $\left(C_{v}\right)$ are plotted in Figure 7. The phenomenon of cavitation affects the coefficient of velocity as evidenced by the fact that $C_{v}$ reduces to 0.78 for a 0.027 " orifice plate as compared to the $C_{v}$ values ranging from 0.95 to 0.99 for non-cavitating orifices. Moreover, the coefficient generally decreases with increasing pressure for a given orifice size. For example, at a pressure of $12,000 \mathrm{psi}$, the $\mathrm{C}_{\mathrm{v}}$ factor for a 0.027 " orifice is 0.78 and increases to 0.82 at an operating pressure of 8,000 psi. 


\subsection{Effect of Reynolds Number}

Although the acceleration effects are a major contribution to the hydraulic losses through orifice plate jet nozzles, the viscous resistance also contributes to the hydrodynamic losses in non-cavitating orifices. However, at Reynolds numbers in the range of $2 \times 10^{5}$, the viscous effect is small and nearly constant. For this reason, the $C_{v}$ factor is generally independent of Reynolds number which includes both velocity and diameter for non-cavitating orifices. In order to evaluate the combined effect of nozzle size and velocity. the coefficient of velocity was plotted as a function Reynolds number as shown in Figure 8. As evidenced by the data, cavitation has an interacting role on the hydrodynamic losses through cavitating orifice plates. Additionally, this figure represents the effect of the size scale on the coefficient of velocity. For cavitating orifice plates, small diameter $\left(0.023^{\prime \prime}\right)$ orifices are more efficient than either $0.025^{\prime \prime}$ or 0.027 " diameter orifices. 
4.0 EFFECT OF NOZZLE SIZE ON THE INTENSITY OF CAVITATION

\section{EROSION}

\subsection{Intensity of Cavitation Erosion}

Cavitation descaling is caused by the collapse of bubbles at or near the solid boundaries guiding high speed flow. The pressure differential produces bubbles which form and collapse and in turn cause the mechanical removal of the scale material. During the cavitation descaling process, a volume of material is removed from the surface as a result of the work done by the bubble collapse forces. The energy absorbed by the material is given by:

$$
E=\Delta V \cdot S
$$

where: $E=$ energy absorbed by the material removed

$$
\begin{aligned}
\Delta \mathrm{V}= & \text { volume of material removed } \\
\mathrm{S}= & \text { scale strength which represents the energy } \\
& \text { absorbing capacity of the material per unit } \\
& \text { volume under the action of the forces }
\end{aligned}
$$

The intensity of cavitation (I) is defined as the power absorbed by the material per unit area and given by:

$$
I=\frac{\Delta V \cdot S}{A \cdot \Delta t}
$$

or

$$
I=\frac{\Delta y}{\Delta t} S
$$


where:

$$
\begin{aligned}
A & =\text { area of cleaning } \\
\Delta y & =\text { mean depth of scale }=\frac{\Delta V}{A} \\
\Delta t & =\text { exposure time }
\end{aligned}
$$

Equation [5] defines the output intensity of cleaning as seen by the scale material. Similarly, an expression can be derived for the bubble collapse intensity as a function of the input intensity to the cleaning process.

Whenever the stress produced by the collapse of the bubble exceeds the yield strength of the scale material, permanent erosion is produced by a single impact. If the associated collapse stress is less than the yield strength, erosion is produced after several bubbles have impacted and collapsed at the surface of the material. Erosion is produced in this case due to the fatigue failure of the material. The actual fracture of a particle from the surface of the material is caused from several overlapping indentations produced by the collapse of many bubbles. For a single impact, the indentation depth $\Delta y^{\prime}$ is related to the scale strength, the impact pressure, and the size of the bubble or jet through the following relationship:

$$
\Delta y^{\prime} \cdot S \propto P_{1} \cdot R
$$


For the case of multiple impacts with a frequency of occurrence, $n$, the rate of indentation is proportional to:

$$
\frac{\Delta y}{\Delta t} \cdot S \propto\left(P_{i}\right) \cdot(R) \cdot(n)
$$

where: $\quad P_{i}=$ impact pressure

$R=$ size of the bubble or jet

$n=$ number of impacts per unit time

The units for the intensity of erosion are watts per square meter $\left(\mathrm{W} / \mathrm{m}^{2}\right)$. The intensity is a quantitative measure of the energy flux to the cleaning surface and a critical design parameter.

4.2 Effect of Nozzle Pressures and Sizes

The cavitation erosion intensity was measured according to the ASTM standard (6) at three pressures $(8,000$ psi, 10,000 psi, and 12,000 psi) for three orifice plate nozzle sizes. The intensity of eroison is shown in Figure 9 as a function of nozzle diameter for the three pressure levels. The intensity decreases as the nozzle diameter increases with the reduction in intensity more pronounced for 12,000 psi as compared to the corresponding decrease for 8,000 psi. For example, the intensity of erosion decreases by a factor of six when the nozzle diameter increases from $0.023^{\prime \prime}$ to 0.027 ". In order to examine the causes for this significant influence 
of pressure on intensity of erosion, the experiments were modified and conducted for constant velocities.

\subsection{Effect of Jet Velocity}

The velocity coefficient is a function of nozzle size and pressure. The relative influence of these two parameters can be evaluated by measuring the intensity of exosion for constant velocities. By controlling the discharge through nozzle, the relationship between the intensity and nozzle size is shown in Figure 10. At relatively low velocities $(800 \mathrm{ft} / \mathrm{sec})$, the nozzle size has no significant influence on the intensity of erosion. For higher velocity ranges $(1,150 \mathrm{ft} / \mathrm{sec})$, the nozzle size has a significant influence on the intensity. The purpose for this data is to establish suitable nozzle diameters and system input parameters to warrant that the intensity is properly controlled. An important design consideration is to insure that the intensity required to clean a given scale formation does not damage the pipe. Therefore, the influence of nozzle distance on the intensity of erosion was established through successive experiments. 
5.0 INFLUENCE OF NOZZLE DISTANCE ON THE INTENSITY OF

CAVITATION EROSION

The thickness and strength of the geothermal scale is a function of the geothermal characteristics of the well, the operating conditions and the size and geometry of pipe. Therefore, under the auspices of this program, it was necessary to develop specific methods and techniques to clean the various types of scale formation without damaging the pipe wall material. This objective was effectively accomplished through an extensive evaluation of the relationship between the erosion intensity and the nozzle distance from the test material, and a series of experiments were conducted in order to measure the intensity of erosion as a function of the nozzle distance. This relationship is shown in Figure 11 for a specific nozzle diameter of $0.023^{\prime \prime}$ at a pressure of 12,000 psi. The intensity of erosion rapidly increases as a function of nozzle distance reaches a maximum value at an offset distance of $0.75^{\prime \prime}$ and then decreases with increasing nozzle distance.

\subsection{Effect of Nozzle Distance}

The maximum intensity achievable with this nozzle design is approximately $12,000 \mathrm{~W} / \mathrm{m}^{2}$. Superimposed on the intensity of erosion/nozzle distance data in Figure 11 is the threshold intensity required to erode the pipe wall material. In order to erode the pipe wall material, a cavitating system 
with an intensity of $20,000 \mathrm{~W} / \mathrm{m}^{2}$ was applied to the wall material with the results shown in Figure 12. At this intensity there is no visible damage to the pipe material after $5 \mathrm{~min}$ utes of cleaning. Initial erosion of the pipe material occurs after 20 minutes. Since the cleaning is accomplished within a few seconds, the pipe wall will not be eroded with the cavitating descaling technique even at an intensity of $20,000 \mathrm{~W} / \mathrm{m}^{2}$. Moreover, there is a substantial margin of safety of approximately $14,000 \mathrm{~W} / \mathrm{m}^{2}$ above the maximum erosion intensity obtained with orifice plate nozzle designs.

In addition to the threshold intensity for pipe material, the associated threshold intensity for scale removal is also shown in Figure 11. The minimum erosion intensity required to clean the silica scale obtained from the Lawrence Livermore Laboratory (LLL) is approximately $90 \mathrm{~W} / \mathrm{m}^{2}$. For the cavitating system identified in Figure 11 , the threshold intensity is achieved for a distance of $2^{\prime \prime}$ from the nozzle. Thus, a scale thickness of approximately 2 " can be cleaned with this nozzle design without affecting the pipe wall material. This type of data were generated for various nozzles at additional velocities and pressures. 


\subsection{Nozzle Size}

Figures 13, 14 and 15 show similar design data for various nozzle sizes at three different velocities. The maximum intesity for the 0.023 " diameter nozzle with a jet velocity of 1,200 fps is Jess than the threshold intensity for pipe material $\left(20,000 \mathrm{~W} / \mathrm{m}^{2}\right)$. Based on a threshold intensity of $90 \mathrm{~W} / \mathrm{m}^{2}$ for geothermal scale, this cavitating system has an effective thickness for scale removal at 1,200 fps which is significantly greater than most scale thicknesses encountered in field operations. The purpose of these charts is to permit the appropriate selection of the nozzle size and jet velocity for specific scale thicknesses occurring at various geothermal power plant sites.

An analysis of the data presented in Figures 13, 14 and 15 indicates that an optimum nozzle diameter size is most effective in removing the maximum thickness of scale. The associated intensity of erosion for the 0.032 " diameter orifice is optimum throughout the entire range of nozzle offset distances. The intensity of erosion characterized by the other nozzles indicate correspondingly lower intensities for a specific offset distance. Furthermore, the peak intensity of erosion is approximately identical for the $0.023^{\prime \prime}$ and the 0.032 " diameter systems and decreases for the 0.037 " diameter nozzle. These design charts relate the nozzle size, the 
jet velocity and the effective thickness of scale removal. From this information, the pump capacity, the pressure and horsepower requirements for the cavitating descaling system can be calculated for specific applications. 


\subsection{EFFECT OF PRESSURE ON CLEANING RATE}

A primary objective of the program was accomplished when the cleaning rate was established as a function of orifice diameter with respect to operating pressure. The cleaning rate was determined for specific geothermal scale obtained from field operating plants.

\subsection{Types of Geothermal Scales Cleaned}

Two types of geothermal scales were investigated during the initial phase of the program. Large diameter pipes (4" and 6" in diameter) were obtained from the Imperial Valley geothermal plant of the San Diego Gas and Electric Co. This pipe contained silica and hard scale $2 "$ to $3 "$ in thickness.

The second scale was supplied by LLL. This scale contained hard silica with substantial amounts of ferritic compounds. The scale had a vitreous texture and fractured with concoidal surfaces. The LLL scale was contained in $3^{\prime}$ pipe sections ranging from $2 "$ to $3^{\prime \prime}$ in diameter. The scale ranged from $1 / 2 "$ to $3 / 4 "$ thick.

\subsection{Depth of Scale Removed}

Detailed measurements were made on the hard silica scale obtained from LLL using a 0.030" diameter nozzle. During these studies, the depth of scale removed in one second for various nozzle pressures was measured with the results shown in Figure 16. No scale was removed during the one second 
exposure for a 1" nozzle distance below a nozzle pressure of 5,000 psi. Above this threshold pressure, the depth of scale removed increases to $1 / 4^{\prime \prime}$ for 7,000 psi nozzle pressure. In order to determine the penetration rate into the scale for longer exposure times ( 60 seconds), the above tests were conducted at lower pressure ranges. The threshold pressure corresponding to a 60 second exposure is significantly reduced to approximately 1,000 psi. The penetration rate increases linearly in depth removal to 2,500 psi and reaches a plateau to 4,500 psi. Beyond 4,500 psi, the depth removal increases rapidly with pressure.

\subsection{Volume of Scale Removed}

As an effective means of utilizing the data generated in Figures 16 and 17 and in order to perform design calculations for the area cleaned as a function of scale thickness, the volume of scale removed was also measured. The relationship between the pressure associated with a one second exposure period and the corresponding volume of scale removed is shown in Figure 18. In contrast to the pressure/thirkness relationship, the volume of scale removed increases linearly from a threshold pressure of 5,000 psi to a maximum of 10,000 psi. For a 60 second exposure period the volume of scale removed increases linearly with pressure from a threshold pressure of 1,000 psi up to approximately 3,500 psi (Figure 19). Above 
this pressure range, the rate of volume removal increases exponentially with pressure. The data governing the rate of depth removal and rate of volume removal establishes the guidelines for estimating the rate of area cleaned for various pipe diameters and scale thicknesses.

6.4 Cleaning Rates Achieved

Preliminary demonstration experiments were conducted on $41 / 2$ " diameter pipe containing geothermal scale from the San Diego Gas and Electric site in the Imperial Valley. The scale ranged from $1.5^{\prime \prime}$ to $2.5^{\prime \prime}$ in thickness and the tested pipe lengths were $4^{\prime}$ to $6^{\prime}$ in length. Typical data generated on the actual cleaning rates achieved with the present system are shown in Figure 20. The measured cleaning rates $\left(\mathrm{in}^{2} / \mathrm{sec}\right)$ are shown plotted as a function of pressure for various nozzle sizes. The nozzle translation rate was maintained constant at 11.25 ips. The cleaning rate increased rapidly with nozzle size at the 3,000 psi pressure. Moreover, at the low pressure there is a significant influence of nozzle diameter on the cleaning rate. The maximum cleaning rate currently achieved with the cavitation descaling technique is approximately 75 $i^{2} / \mathrm{sec}$ for the geothermal scale from the San Diego Gas and Electric Imperial Valley site. 


\subsection{Quality of Cleaned Surfaces}

The cavitating descaling system has removed geothermal scale without damage to the adjoining section of pipe. Moreover, no scale residue is remaining on the pipe wall after cleaning. Figure 21 shows a typical longitudinal section of pipe indicating the scale thickness and the quality of the cleaned surface after application of the descaling technique. Figure 22 is a photographic view of a 2 ' length of pipe section emphasizing the uniformity in the quality of cleaned surface. Furthermore, the fragmented and broken chips of scale from the application of the technique range from $1 / 8^{\prime \prime}$ to $1 / 4^{\prime \prime}$ in size and are easily flushed by the water used in the cleaning operations. 


\subsection{CONCLUSIONS AND RECOMMENDATIONS}

The following specific conclusions are summarized as a result of the initial feasibility for utilizing the phenomenon of cavitation as a descaling technique for pipes and tubes used in geothermal energy plants.

1. The coefficient of velocity for cavitating nozzles as a function of jet velocity is significantly lower as compared to the performance of non-cavitating nozzles. A size scale effect has been established for cavitating jet nozzles and determined to be an important design criteria in estimating the power requirements of the pump/motor combination for cleaning geothermal scales.

2. The intensity cavitation erosion does not depend upon the nozzle diameter at low $(3,000 \mathrm{psi})$ nozzle pressures. However, at pressures in the range of 1,200 psi, the intensity of erosion increases considerably with decreasing nozzle diameter.

This result provides design information in selecting the proper nozzle size and pumping pressure for the appropriate type of geothermal scale.

3. The intensity of erosion increases with increasing nozzle distance from the scale, reaches a maximum value and then decreases. This relationship between the cavitating system and the offset distance provides for the selection of the proper nozzle size and jet velocity for removing a given scale thickness without damaging the adjoining pipe wall. Moreover, a substantial margin of safety exists between the maximum intensity of erosion for the nozzles tested and the threshold intensity of erosion for pipe wall materials encountered in the field. 
4. Additional design data for different type of scales obtained from various geothermal power plant sites are needed to insure that proper cleaning systems and procedures are developed for the general use of geothermal industry.

5. The threshold pressure for cleaning fleld scale varies from $1,000 \mathrm{psi}$ to $5,000 \mathrm{psi}$ depending upon a respective exposure period of one second or one minute. Additionally, the effective scale thickness that is cleaned by the cavitation descaling technique is a function of the nozzle diameter and the velocity of the jet.

6. The engineering studies conducted under the first phase of the cavitation descaling program have clearly established the feasibility of utilizing this technique for field applications. It is recommended that the program be extended to include field demonstration of the equipment and procedure. 


\section{REFERENCES}

1. Livermore, Lawrence, "Geothermal Development of the Salton Trough, California and Mexico," UCRL-51775, April 1, 1975.

2. Thiruvengadam, A. P., "The Concept of Erosion Strength," ASTM, Special Technical Publication 408, 186-213, 1967.

3. Thiruvengadam, A: P., "Prevention and Cure of Cavitation Erosion," Naval Research Reviews, May 1972.

4. Heymann, F. J., "On the Time Dependence of the Rate of Erosion Due to Impingement or Cavitation," Erosion by Cavitation or Impingement, ASTM STP 408, p. 70, 1967.

5. Thiruvengadam, A.P., "Scaling Laws for Cavitation Erosion," Proceedings of Symposium on High Speed Flow of Water, International Union of Theoretical and Applied Mechanica, Leningrad, USSR, 1971.

6. Hammitt, F. G., et. al. "ASTM Round Robin Test with Vibratory Cavitation and Liquid Impact Facilities," Materials Research and Standards, Vol. 10, 16-24, 1970. 


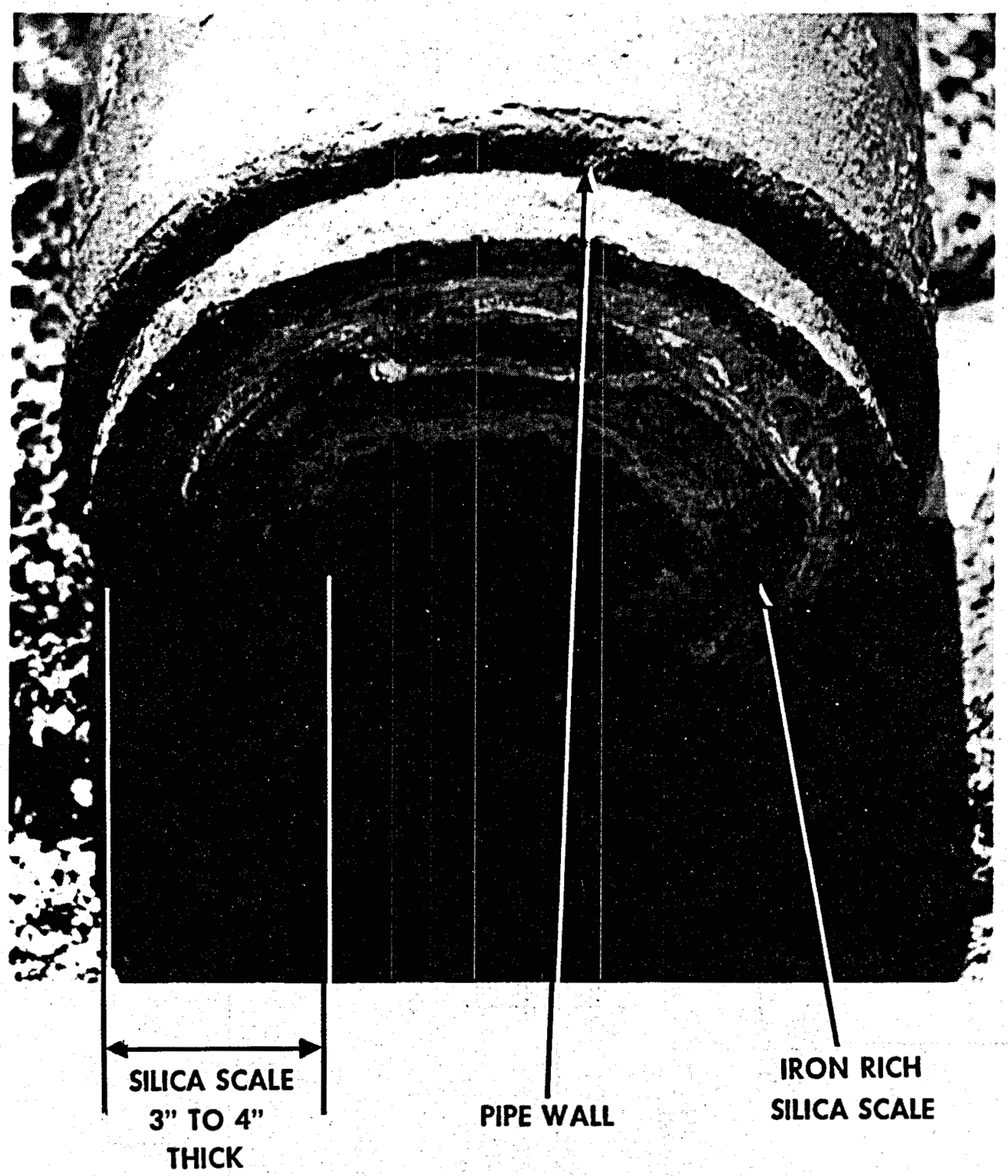

FIGURE 1 SEVERE SCALING OF FEEDER PIPES LEADING TO FLASHERS AND SCRUBBERS. MINERAL DEPOSITS 3" TO 4" THICK HAVE ACCUMULATED ON FEEDER PIPES IN OPERATION 


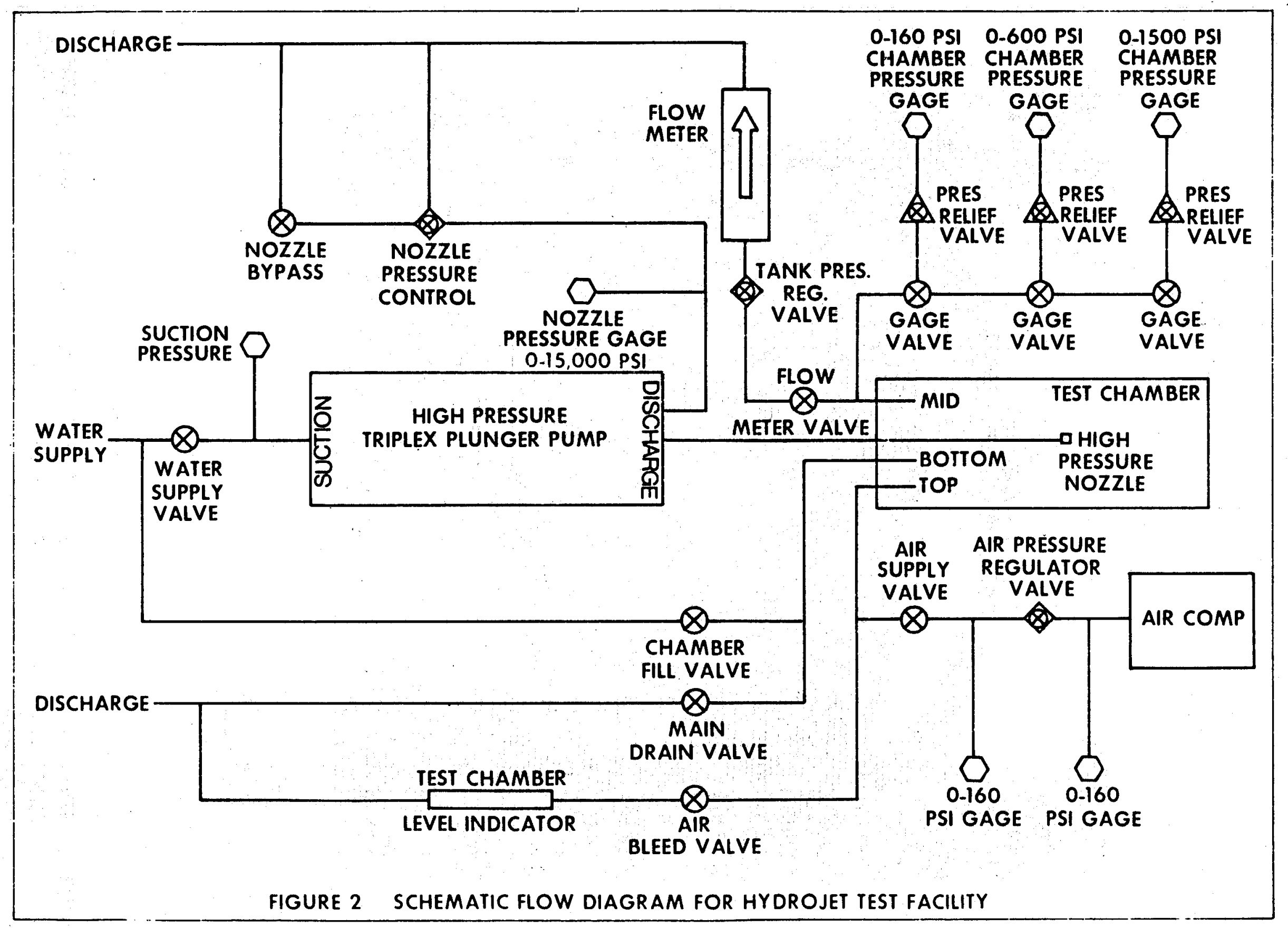




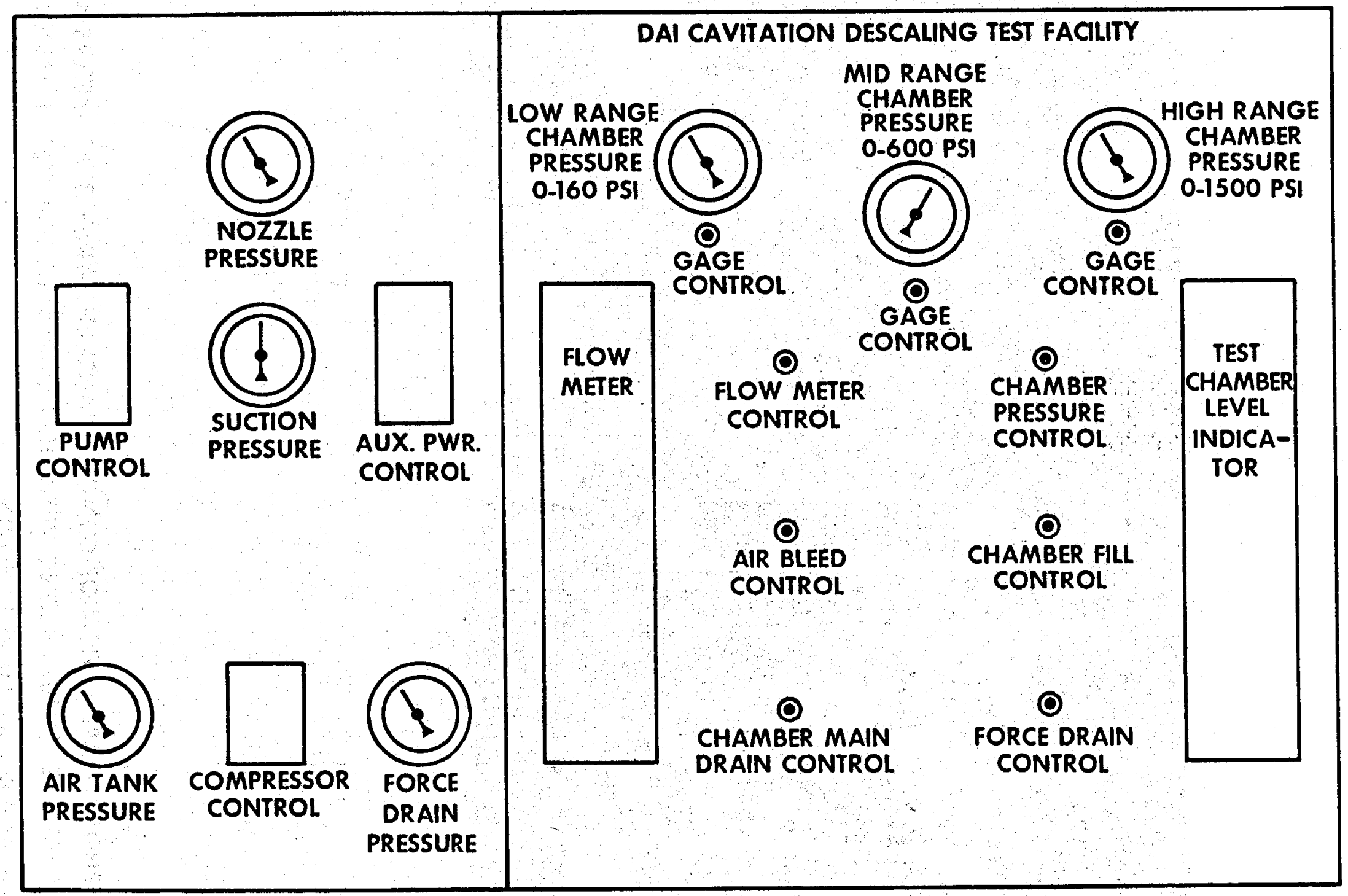

FIGURE 3 SCHEMATIC OF CONTROL PANEL FOR CAVITATION DESCALING TEST FACILITY 


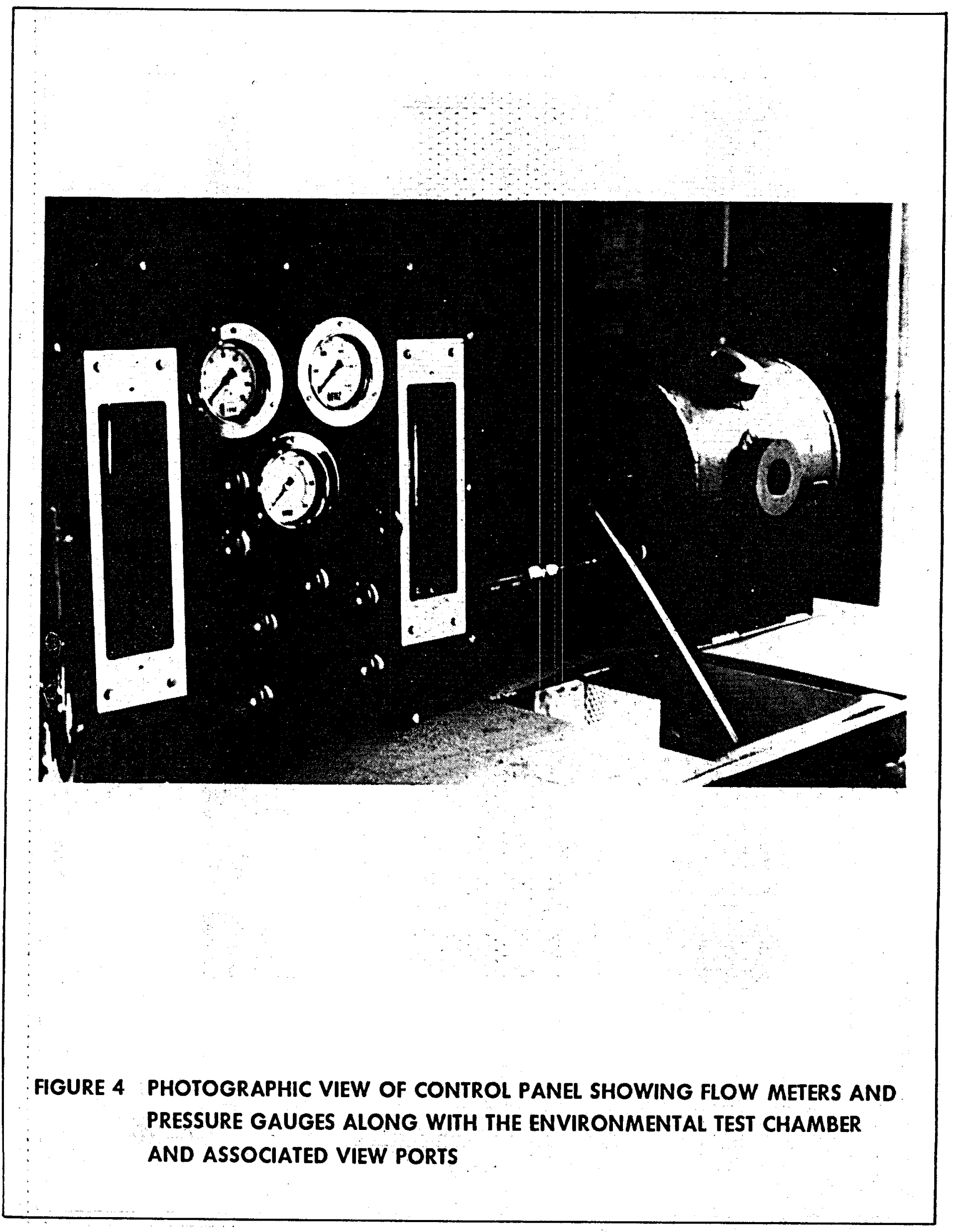




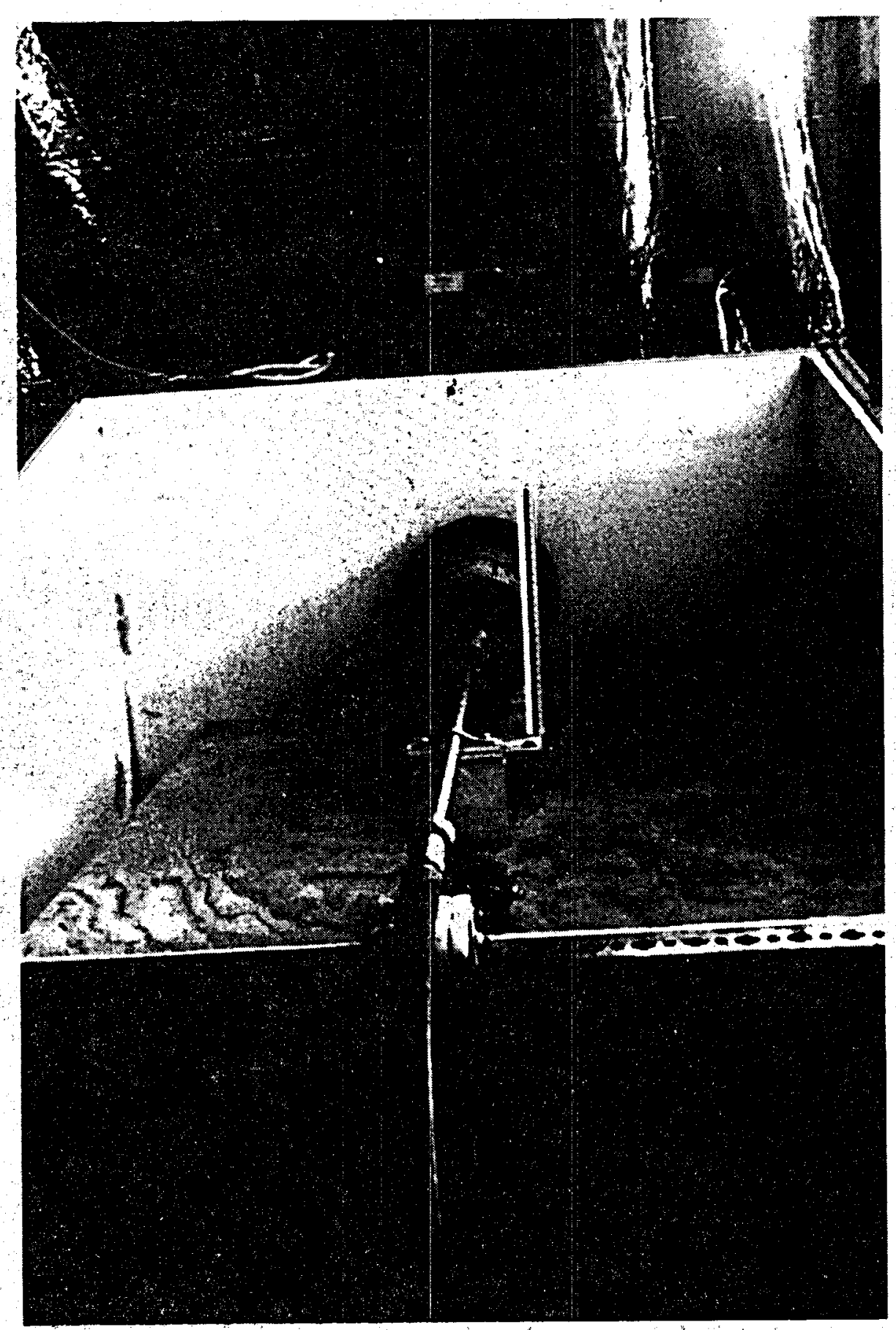

FIGURE 5 END SECTION VIEW OF TEST CHAMBER INDICATING DESCALING LANCE WITH SECTION OF SCALED PIPE 


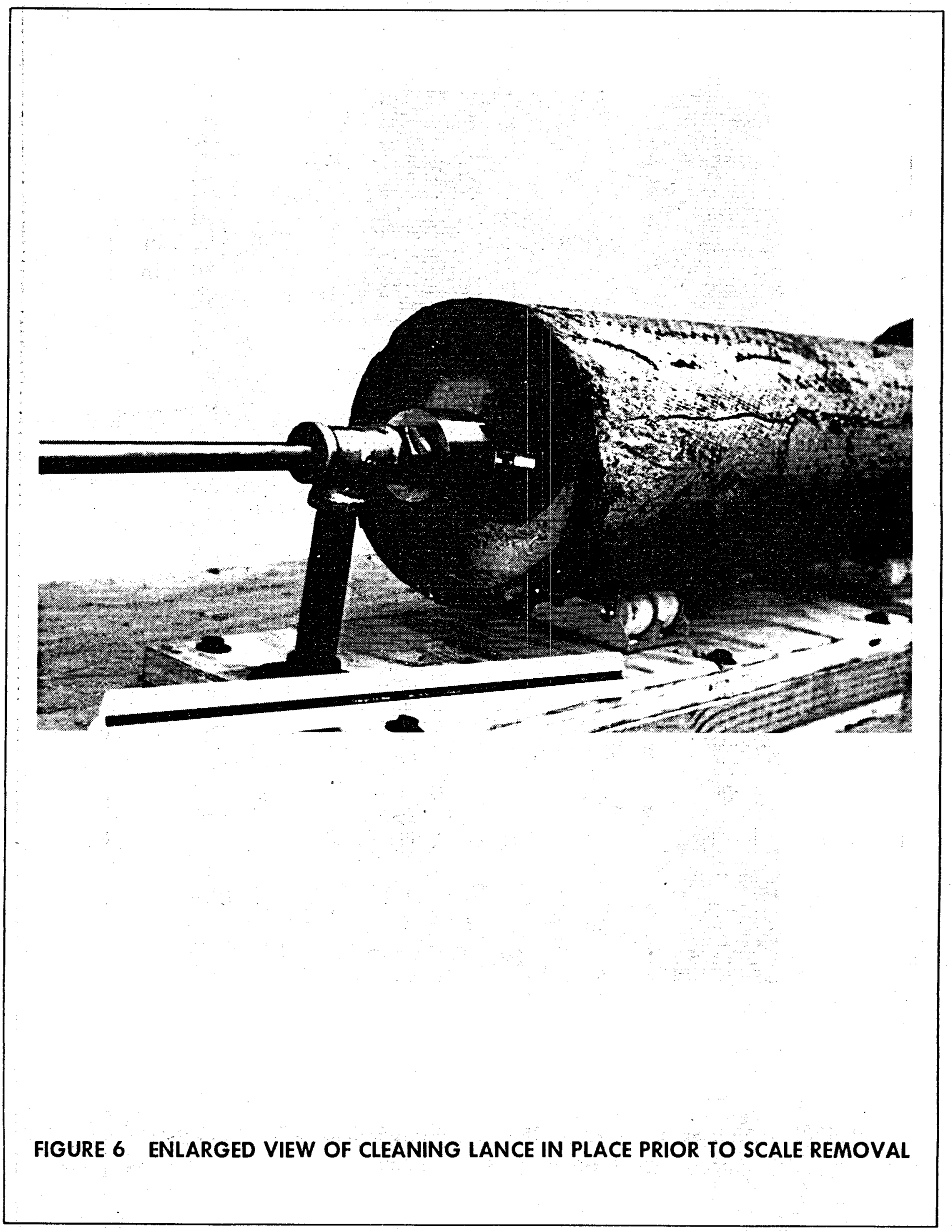




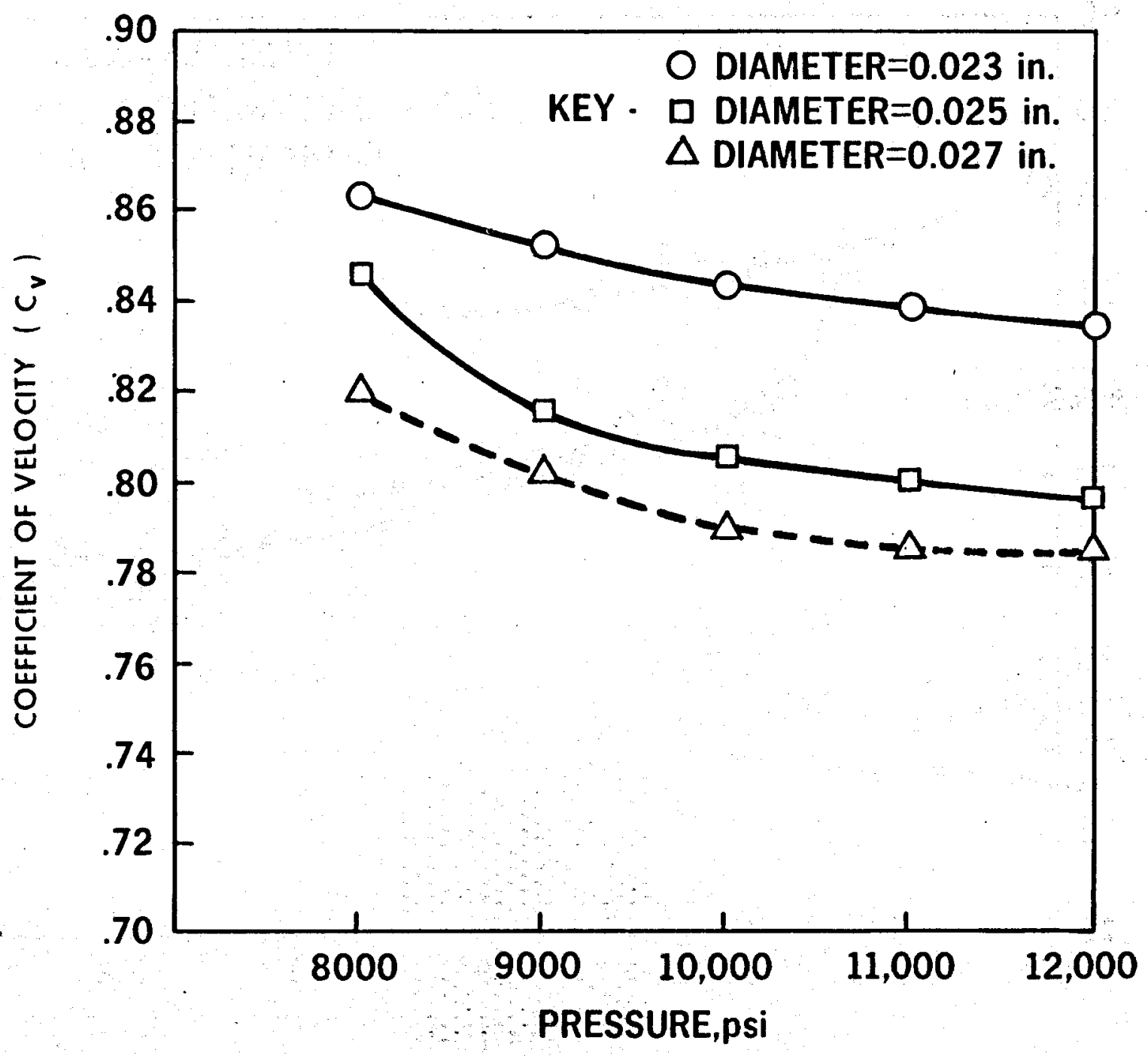

FIGURE 7 LOSS COEFFICIENT FOR CAVITATING NOZZLES 


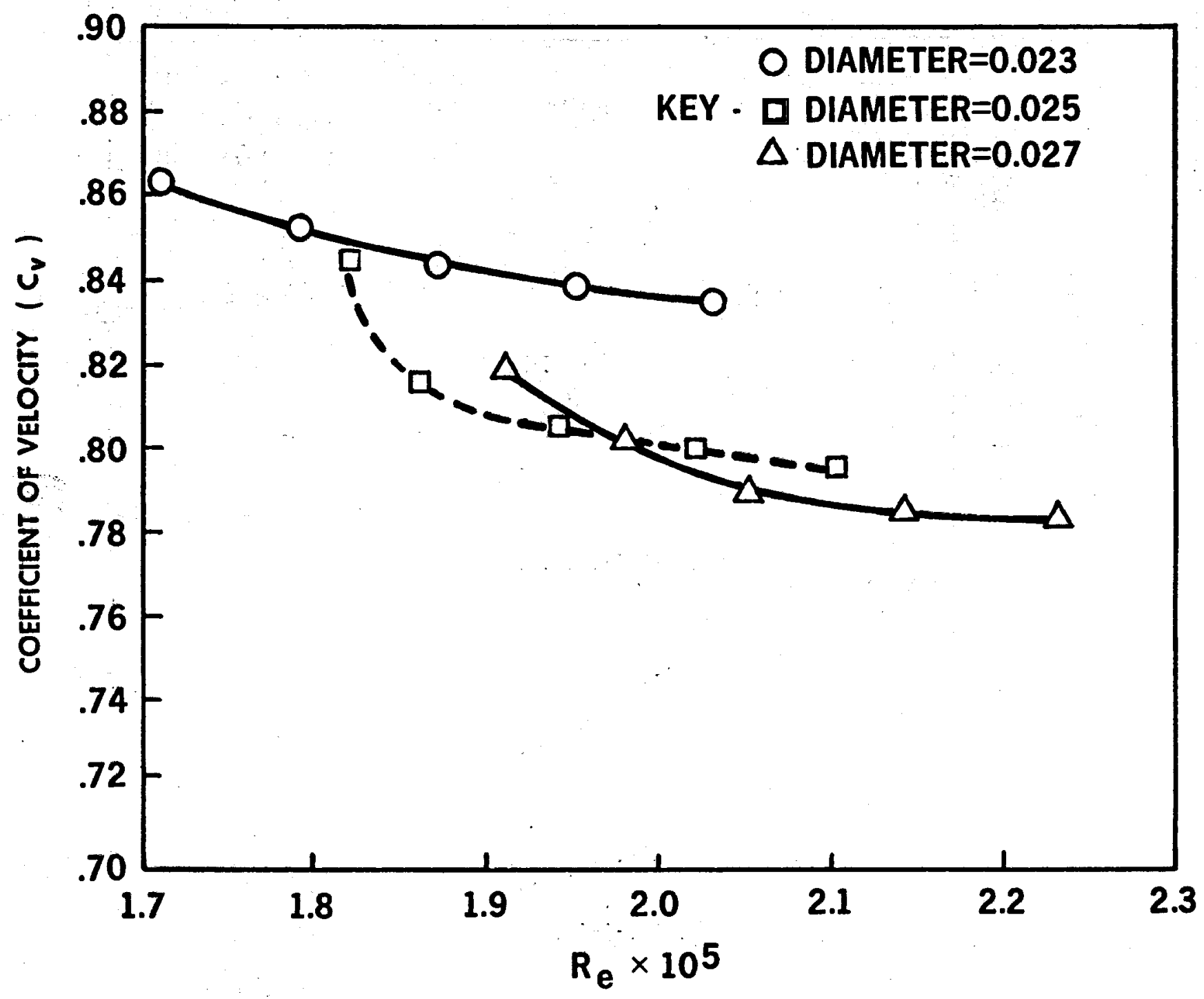

FIGURE 8 EFFECT OF REYNOLDS NUMBER ON COEFFICIENT OF VELOCTTY 


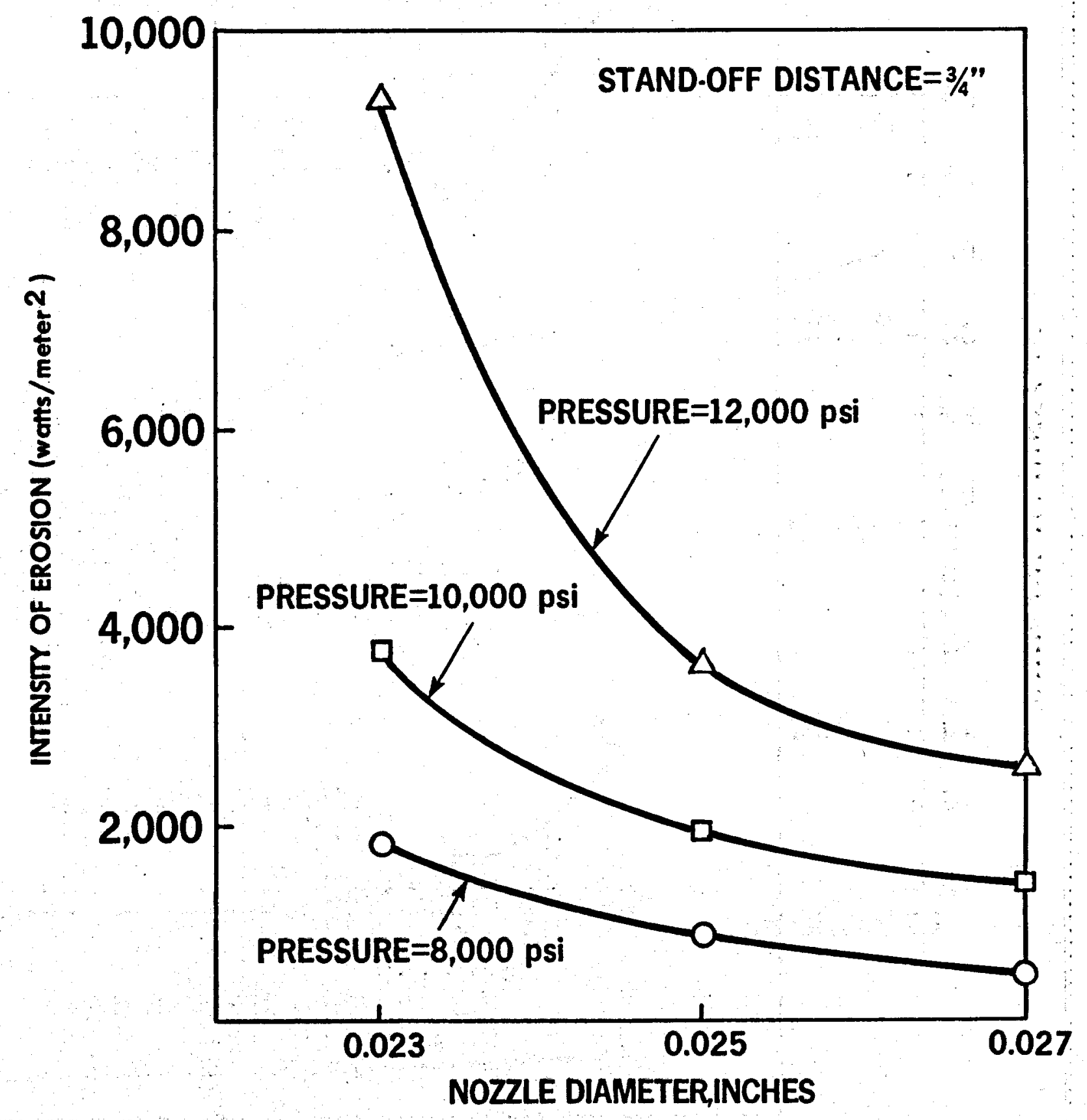

FIGURE 9 INTENSITY OF CAVITATION EROSION vs. NOZZLE SIZE AT CONSTANT PRESSURE 


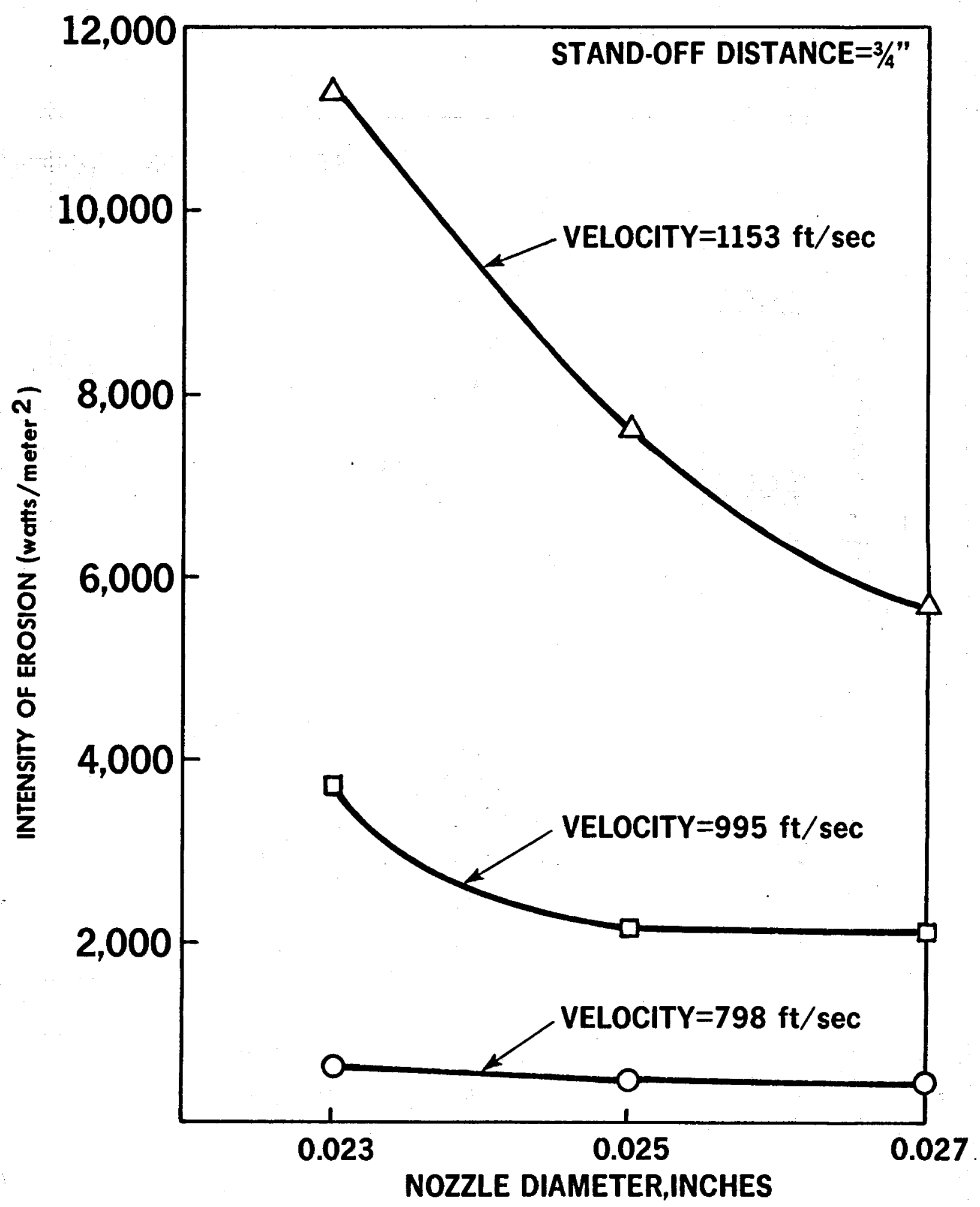

FIGURE 10 INTENSITY OF CAVITATION EROSION vS. NOZZLE SIZE AT CONSTANT VELOCITIES 


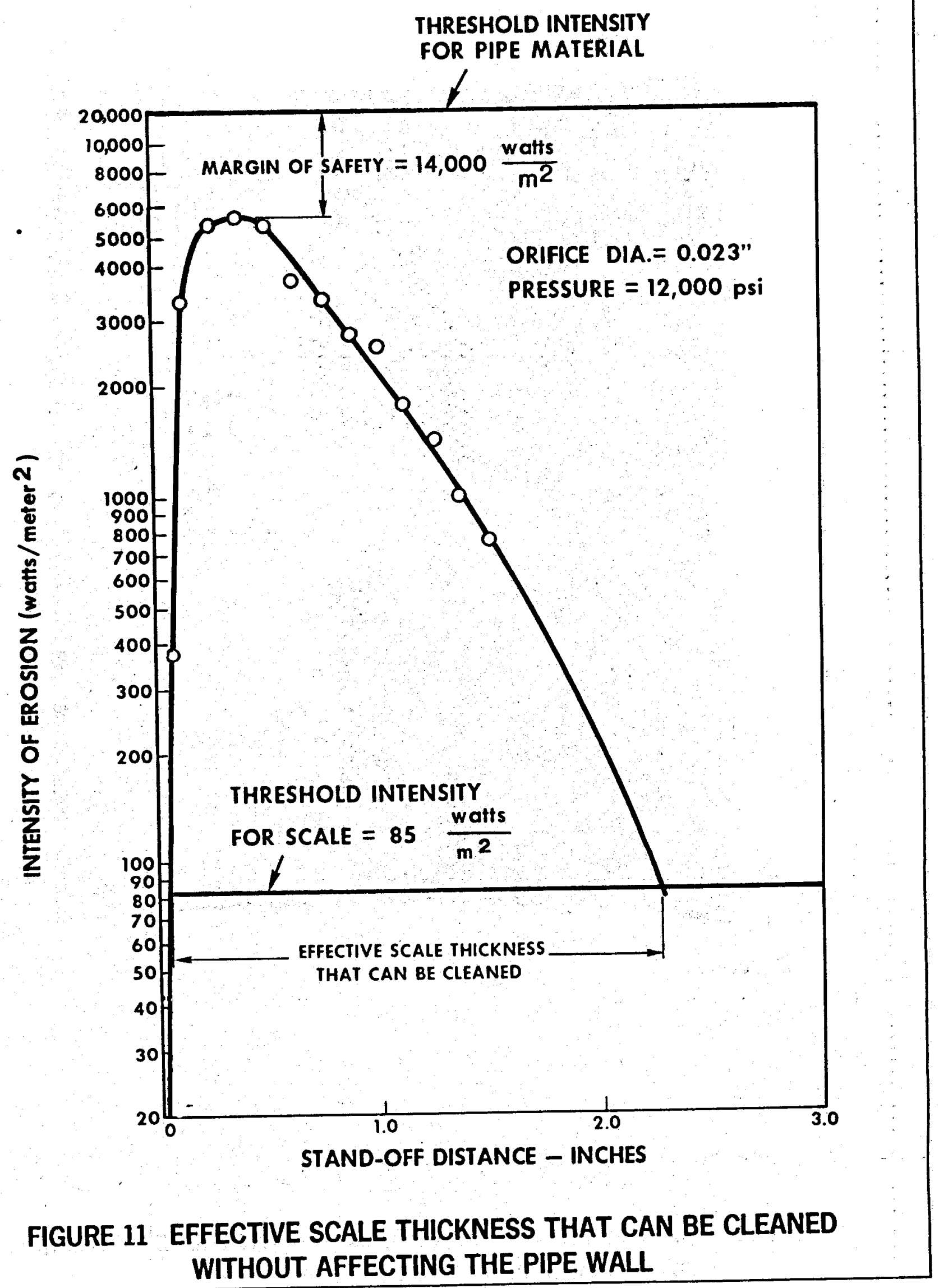




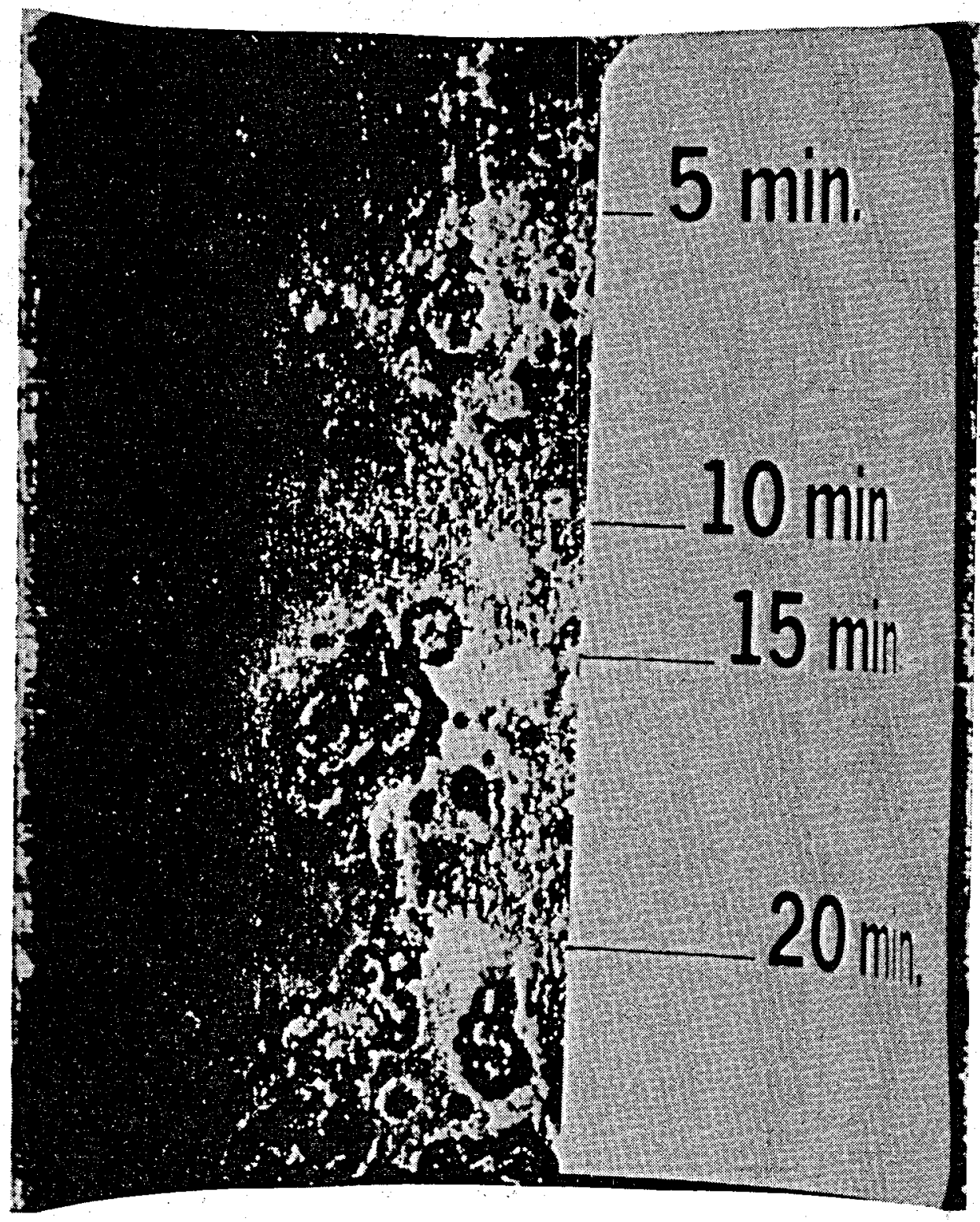

FIGURE 12 THE EFFECT OF A CAVITATING SYSTEM ON THE PIPE WALL MATERIAL WITH AN INTENSITY OF $20,000 \mathrm{~W} / \mathrm{m}^{2}$. 


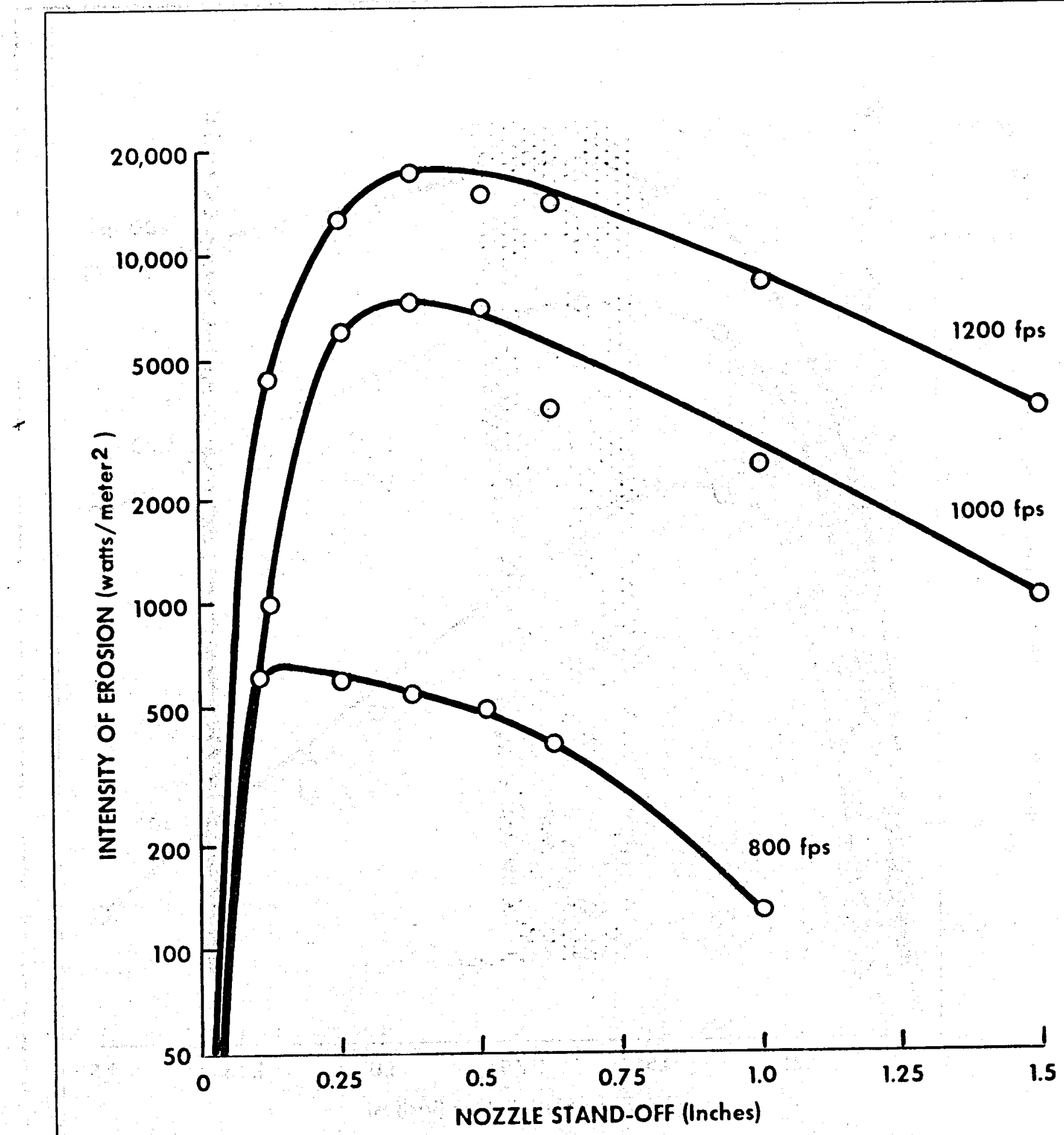

FIGURE 13 EFFECT OF STAND-OFF DISTANCE ON THE INTENSITY OF CAVITATION EROSION FOR A 0.023 INCH DIAMETER NOZZLE 


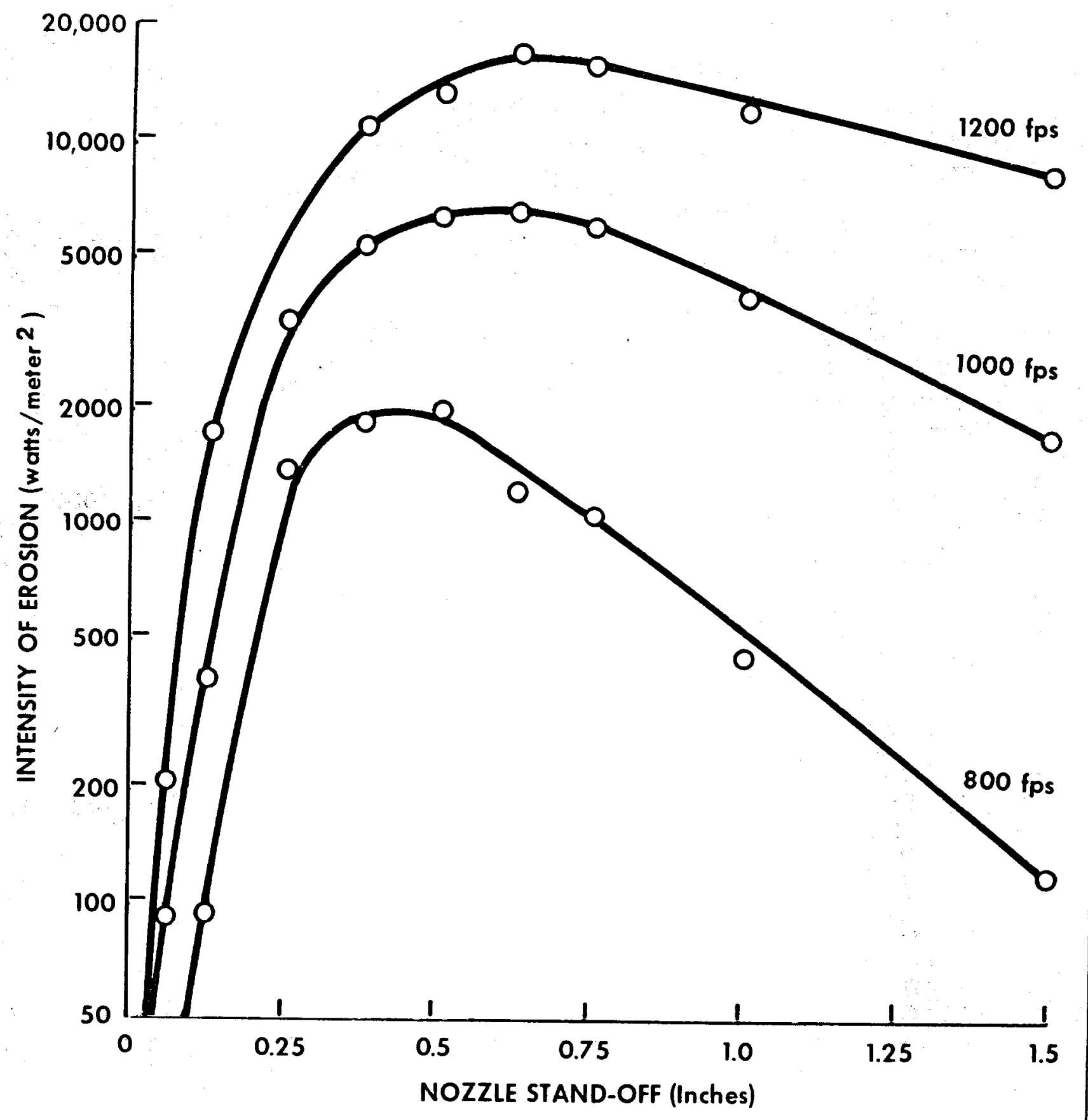

FIGURE 14 EFFECT OF STAND-OFF DISTANCE ON THE INTENSITY OF CAVITATION EROSION FOR A 0.032 INCH DIAMETER NOZZLE 


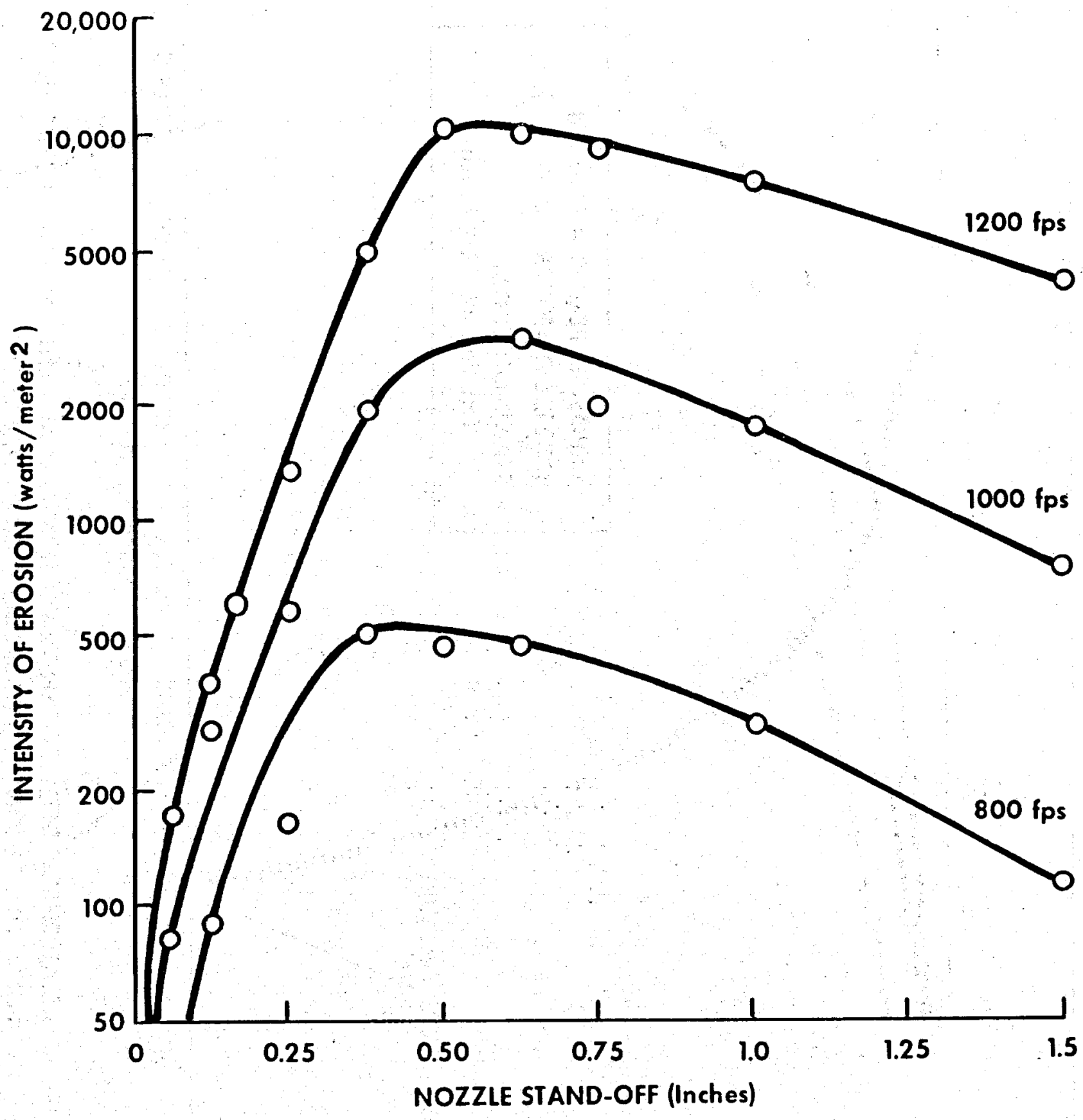

FIGURE 15 EFFECT OF STAND-OFF DISTANCE ON THE INTENSITY OF CAVITATION EROSION FOR A 0.037 INCH DIAMETER NOZZLE 


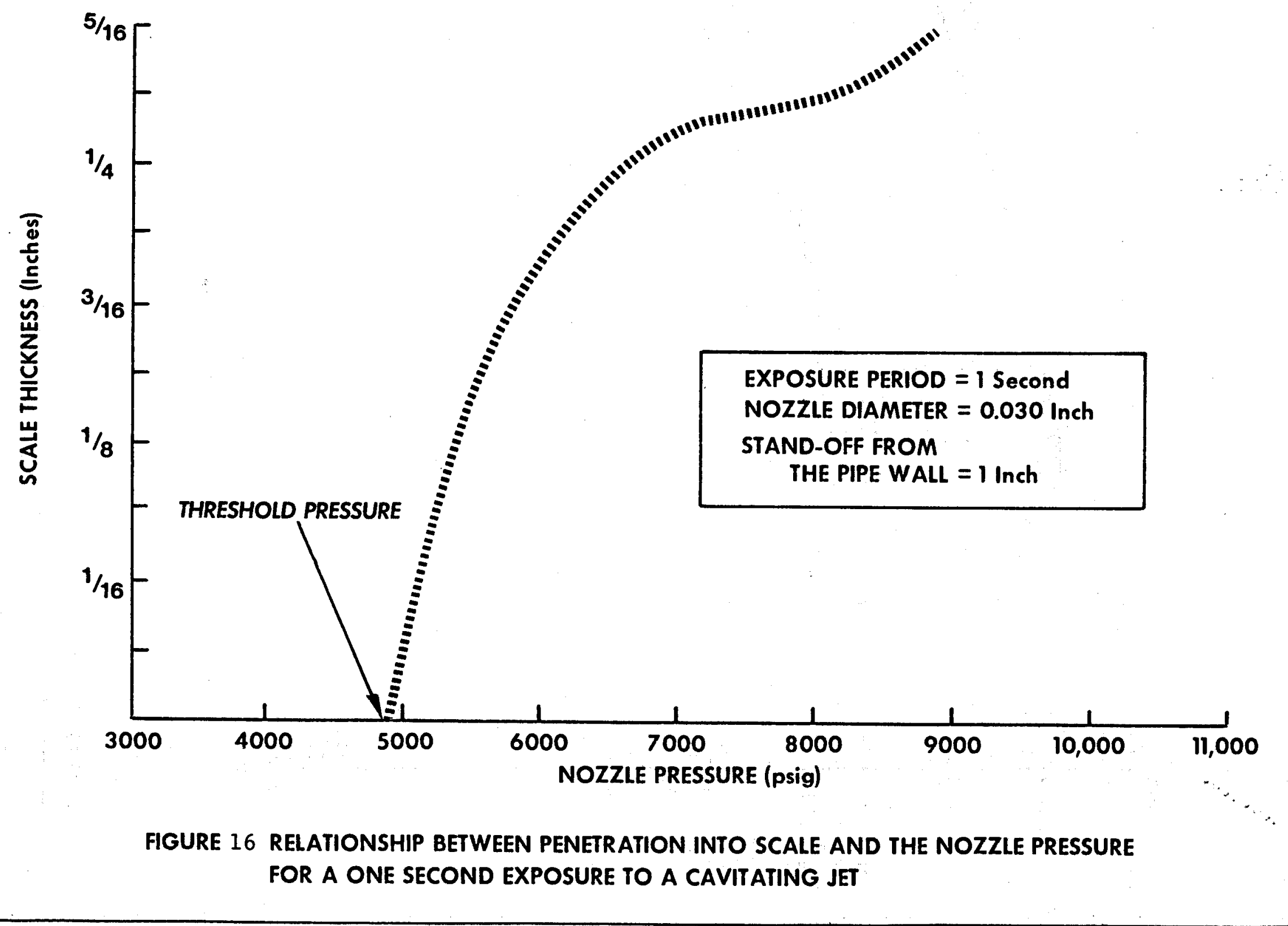




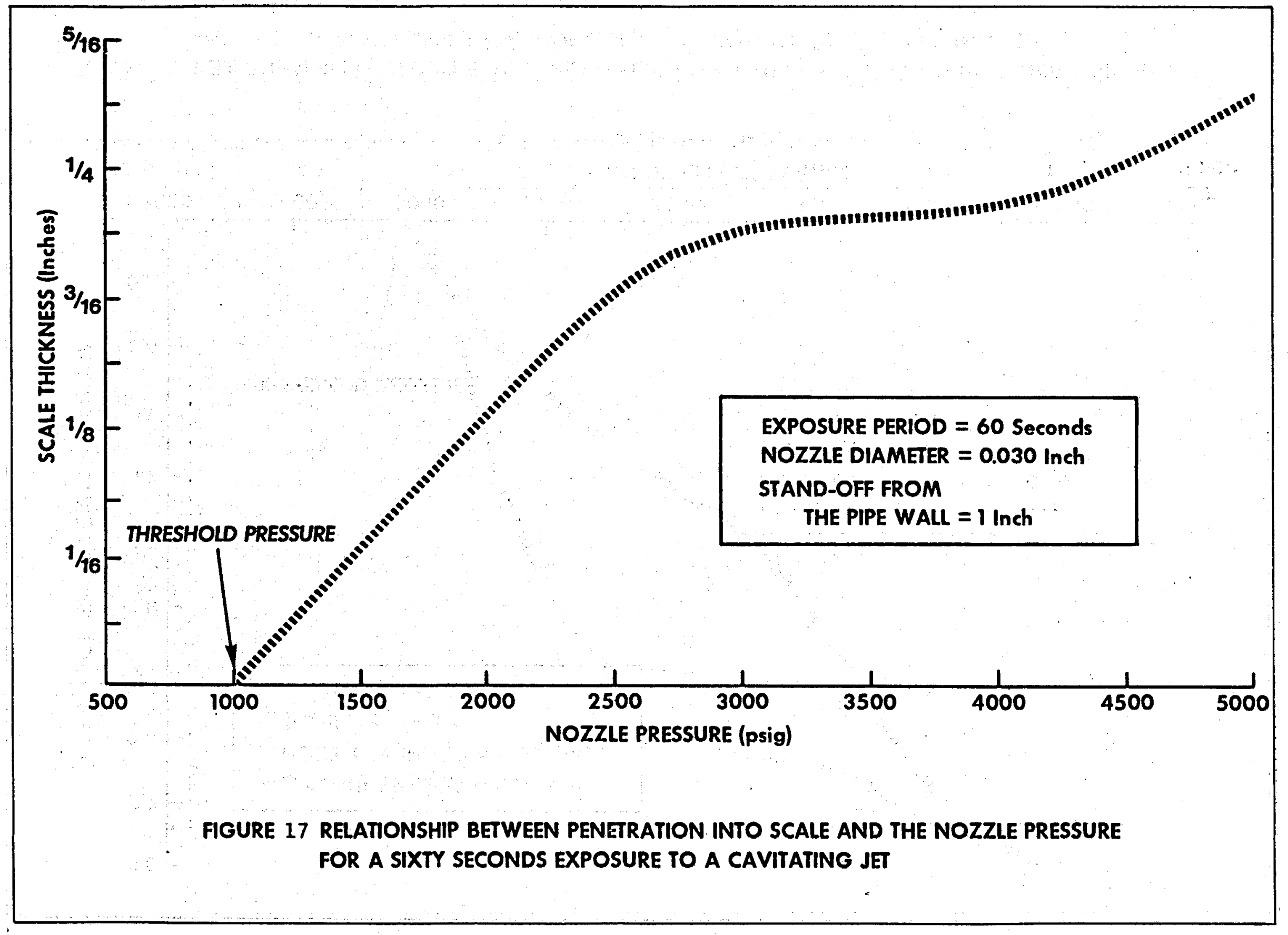




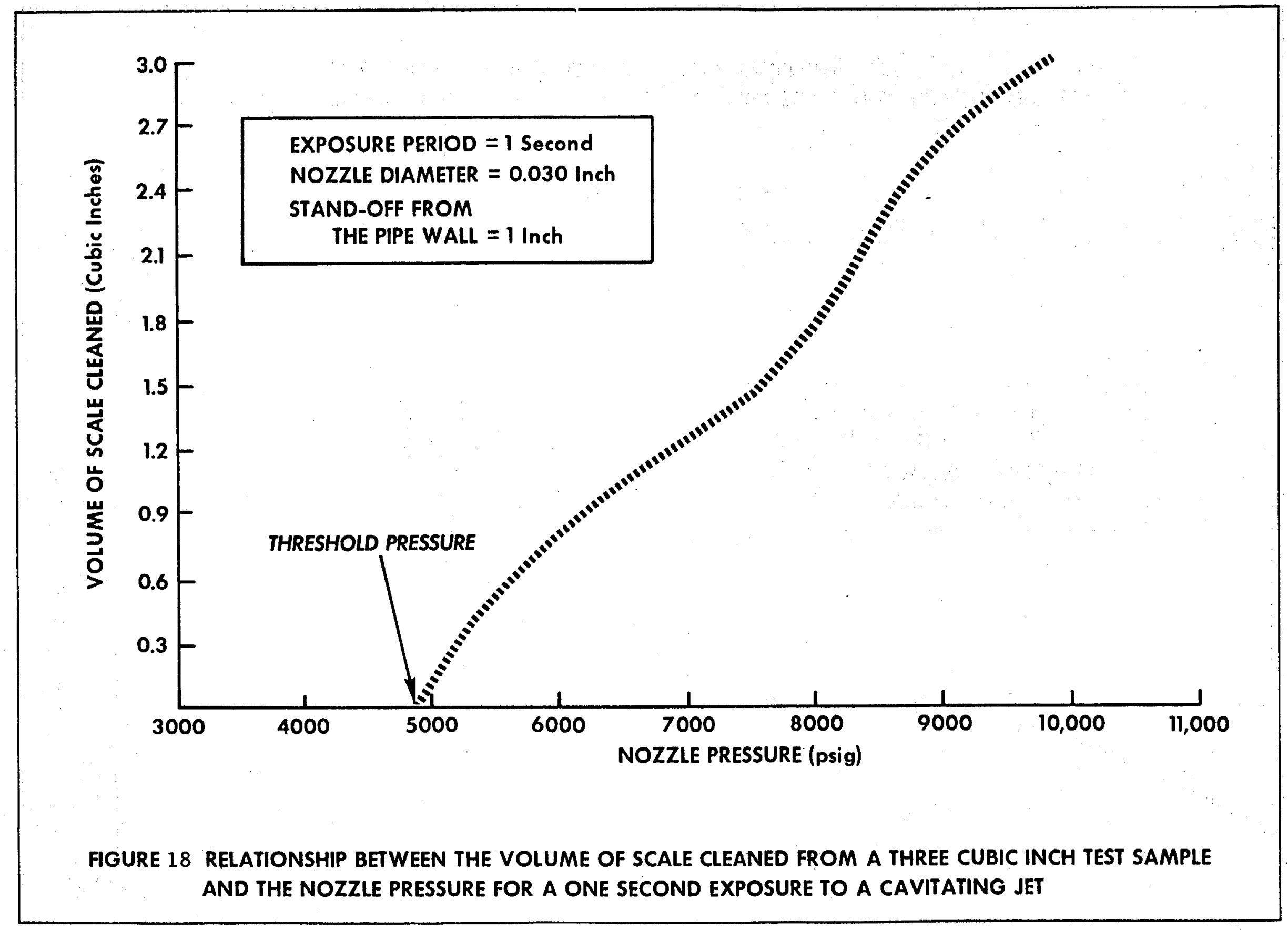




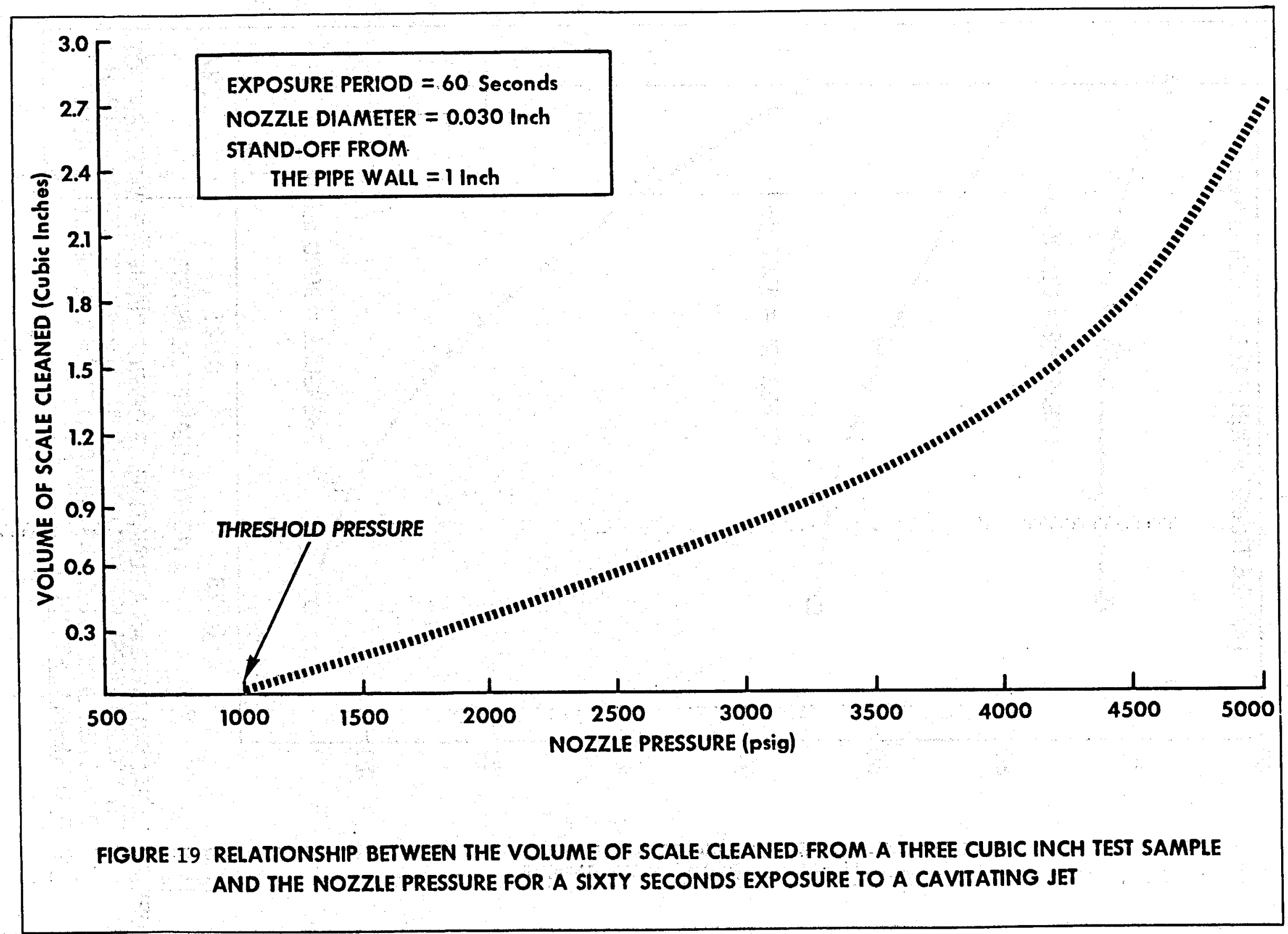




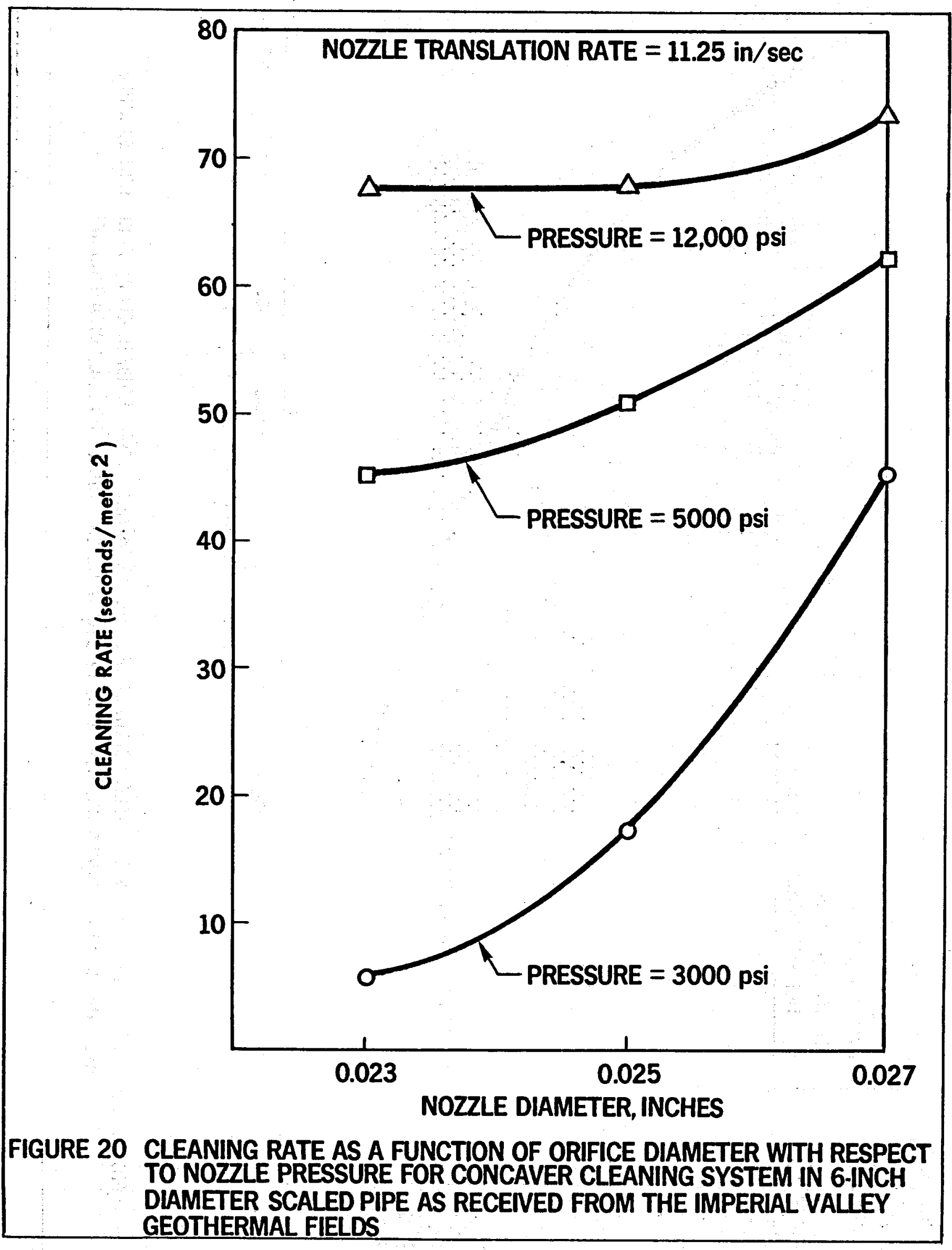



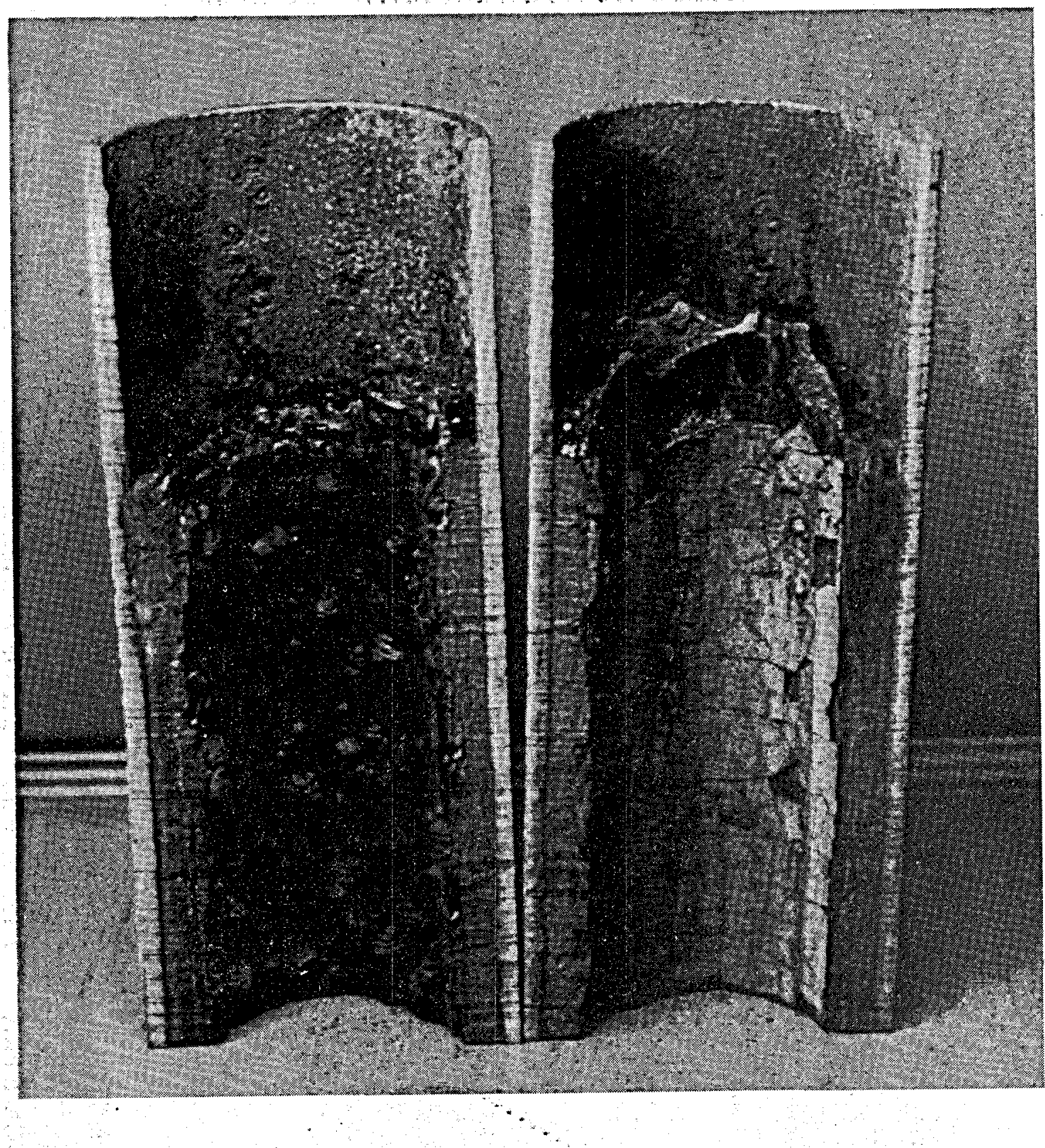

FIGURE 21 LONGITUDINAL SECTION OF PIPE SHOWING THICKNESS OF SCALE AND QUALITY OF CLEANED SURFACE AFTER APPLICATION OF DESCALING TECHNIQUE. 

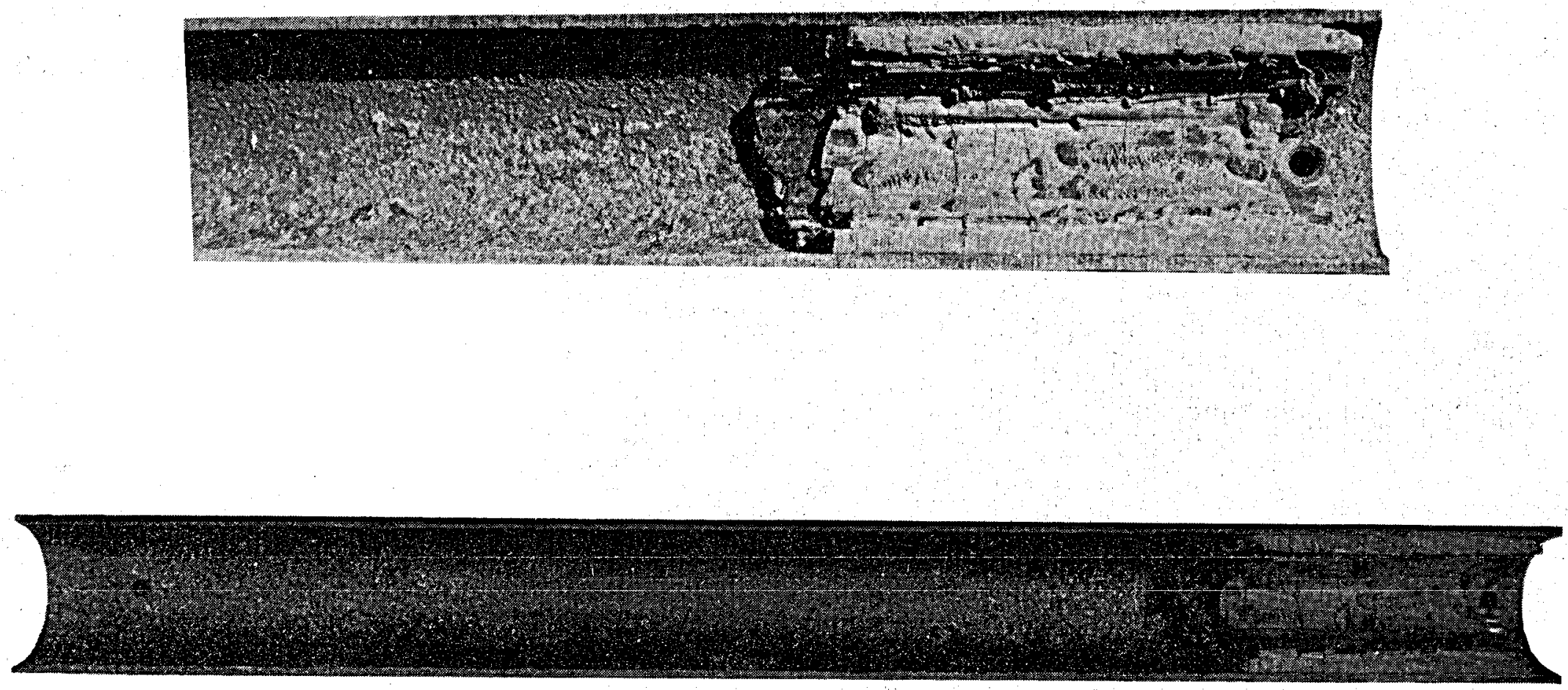

FIGURE 22 PHOTOGRAPHIC VIEW OF TWO FOOT LONGITUDINAL SECTION SHOWING EFFECT OF CAVITATION CLEANING AND THE INITIAL SCALE PRIOR TO THE APPLICATION OF THE TECHNIOUE. 